Retraction

\title{
Retracted: Growth Responses and Leaf Antioxidant Metabolism of Grass Pea (Lathyrus sativus L.) Genotypes under Salinity Stress
}

\section{International Scholarly Research Notices}

Received 7 August 2016; Accepted 7 August 2016

Copyright (C) 2016 International Scholarly Research Notices. This is an open access article distributed under the Creative Commons Attribution License, which permits unrestricted use, distribution, and reproduction in any medium, provided the original work is properly cited.

International Scholarly Research Notices has retracted the article titled "Growth Responses and Leaf Antioxidant Metabolism of Grass Pea (Lathyrus sativus L.) Genotypes under Salinity Stress" [1]. The article was found to contain images with signs of duplication and manipulation in Figures 5(a), 5(b), 6(a), and 6(b), and duplication from Talukdar D. Plant Growth and Leaf Antioxidant Metabolism of Four Elite Grass Pea (Lathyrus sativus) Genotypes, Differing in Arsenic Tolerance. Agric Res (2013) 2: 330. doi:10.1007/s40003-0130085-3 in Figure 6.

\section{References}

[1] D. Talukdar, "Growth responses and leaf antioxidant metabolism of grass pea (Lathyrus sativus L.) genotypes under salinity stress," ISRN Agronomy, vol. 2013, Article ID 284830, 15 pages, 2013. 


\title{
Growth Responses and Leaf Antioxidant Metabolism of Grass Pea (Lathyrus sativus L.) Genotypes under Salinity Stress
}

\author{
Dibyendu Talukdar
}

Department of Botany, R.P.M. College, University of Calcutta, Uttarpara, Hooghly, West Bengal 712 258, India

Correspondence should be addressed to Dibyendu Talukdar; dibyendutalukdar9@gmail.com

Received 3 September 2013; Accepted 17 November 2013

Academic Editors: A. Berville and F. Volaire

Copyright (C 2013 Dibyendu Talukdar. This is an open access article distributed under the Creative Commons Attribution License, which permits unrestricted use, distribution, and reproduction in any medium, provided the original work is properly cited.

\begin{abstract}
Response of six improved grass pea genotypes to prolonged salinity stress was investigated on seedlings grown in pot experiment using $150 \mathrm{mM} \mathrm{NaCl}$ up to 60 days of growth after commencement of treatment (DAC). $\mathrm{NaCl}$ exposure significantly reduced growth potential of varieties PUSA-90-2 and WBK-CB-14, but no such effect was observed in varieties B1, BioL-212 and in two mutant lines LR3 and LR4. A time-bound measurement at 15,30 and 60 DAC revealed significant reduction in plant dry matter production, orchestrated through abnormally low capacity of leaf photosynthesis accompanied by low $\mathrm{K}^{+} / \mathrm{Na}^{+}$ratio and onset of oxidative stress in all six genotypes at 15 DAC and the extension of the phenomena in PUSA-90-2 and WBK-CB-14 to 60 DAC. High superoxide dismutase (SOD) activity coupled with low ascorbate redox and declining ascorbate peroxidase (APX) and catalases (CAT) levels led to abnormal rise in $\mathrm{H}_{2} \mathrm{O}_{2}$ content at reproductive stage (30 DAC) in the latter two genotypes, consequently, resulting in NaClinduced oxidative damage. $\mathrm{H}_{2} \mathrm{O}_{2}$ level in the rest of the four genotypes was modulated in a controlled way by balanced action of SOD, APX and CAT, preventing oxidative damage even under prolonged NaCl-exposure. Enzyme isoforms were involved in regulation of foliar $\mathrm{H}_{2} \mathrm{O}_{2}$-metabolism, which was critical in determining As tolerance of grass pea genotypes.
\end{abstract}

\section{Introduction}

Soil salinity is one of the most severe abiotic stresses affecting production of the crops worldwide $[1,2]$. This problem is more severe in arid and semiarid regions, and legume plants already face a notable impact of salt stress in these regions [3, 4]. The legume family is the second only to the cereals in their importance to mankind [3], but unfortunately, improvements of this group of plants for their tolerance against soil salinity stress have not kept pace with those of cereals and oil seeds.

Salinity induces oxidative stress through the generation of reactive oxygen species (ROS) within the plant cells [5]. The resultant damage is generally manifested by different alterations at cellular level including membrane lipid peroxidation, electrolyte leakage, and sometimes over accumulation of hydrogen peroxide $\left(\mathrm{H}_{2} \mathrm{O}_{2}\right) \cdot \mathrm{H}_{2} \mathrm{O}_{2}$ is a highly diffusible ROS within plant cell and its dual roles as a stress-inducer and at the same time as a signaling molecule to upregulate primary antioxidant defense during oxidative stress have been increasingly recognized in different crops including legumes [6-8]. Among the prominent enzymatic system involved in ROS scavenging, SOD constitutes the first line of defense, but it steadily generates $\mathrm{H}_{2} \mathrm{O}_{2}$ during dismutation of superoxide radicals mainly by the action of its membrane bound $\mathrm{Cu} / \mathrm{Zn}$ isoforms $[9,10]$. This $\mathrm{H}_{2} \mathrm{O}_{2}$ is readily scavenged by ascorbate peroxidase (APX) using AsA as its exclusive cofactor within the AsA-GSH cycle and by catalases (CAT) outside this cycle [11]. These three prominent $\mathrm{H}_{2} \mathrm{O}_{2}$ metabolizing enzymes hold the key in controlling $\mathrm{H}_{2} \mathrm{O}_{2}$ level during the onset of salinity-induced oxidative stress in plants $[4,11]$. In addition, plants accumulate different osmo-regulatory substances under stress and, among them, the role of proline is being debated most. Besides cytosolic osmotic adjustment, compatible solutes possibly play vital roles in stabilizing the structure and activities of enzymes and protein complexes, scavenging ROS and maintaining the integrity of membranes under dehydration stress conditions $[12,13]$. Another function of compatible solutes may be in maintaining cytosolic $\mathrm{K}^{+}$homeostasis by preventing $\mathrm{NaCl}$ induced $\mathrm{K}^{+}$leakage from the cells [14].

Grass pea (Lathyrus sativus L.) is a hardy cool-season legume crop, cultivated for both forage and grain in Indian 
Subcontinent, Australia, the Mediterranean regions, North Africa, parts of North Europe, and in South America [14, 15]. This crop is highly valued for its remarkable capacity to grow in almost every agroclimatic condition with marginal or often no input and is a promising source of seed protein, minerals, and antioxidant compounds like flavonoids and other polyphenolic compounds [16-19]. The property of type II diabetes-related enzyme inhibition capacity in this crop has recently been revealed in raw and different processed forms of seeds $[19,20]$. In recent times, genetic improvement programs for desirable agronomic features particularly high yield and low antinutritional factors including neurotoxin $(\beta$-ODAP) have gained momentum in grass pea with development of robust mutation genetic and cytogenetic stocks [21-29]. However, like many other pulses, grass pea faces diverse types of abiotic stresses such as drought, salinity, metal, and weed-induced toxicity [30-33]. Exposure to $\mathrm{NaCl}$-significantly modulated early seedling growth and leaf biochemical parameters in grass pea genotypes under salinity stress [34], and quite alarmingly, enhanced the seed neurotoxin content in grass pea genotypes [34]. Vaz Patto et al. [30] reported good adaptability to salinity stress in the Mediterranean germplasm, while reduction of growth was known in Iranian germplasms of grass pea [35]. Although vast areas under grass pea cultivation are now salinityaffected and increasing salinity is posing great danger for broader introduction of promising genotypes (high yield with low seed neurotoxin content), virtually nothing is known about growth responses and primary antioxidant defense mechanism of this crop. As salt tolerance mechanisms may vary from species to species and at different developmental stages, understanding of specific physiological and intrinsic biochemical mechanism in relation to plant growth is extremely necessary to develop screening markers for genetic improvement of salinity tolerance in crop plants [36]. Along with growth parameters, the antioxidant defense responses are often regarded as one of the important criteria for determining tolerance level of plants to salinity stress [37]. Hence, the object of the present study was set to evaluate the effects of salt stress on growth responses of different grass pea genotypes and to analyze the primary antioxidant defense response in leaves of control and treated plants for better understanding the mechanisms of salt tolerance in grass pea.

\section{Materials and Method}

2.1. Plant Materials and Field Location. The experimental materials comprised six elite grass pea (Lathyrus sativus L.) genotypes [34], namely, B1, BioL-212, PUSA-90-2, WBK-CB14, LR3, and LR4. Cultivars (var.) B1, BioL-212 and PUSA-902 were selected in the present study for their high yield and low seed toxin levels $(<0.2 \%)$ and introduction of cultivation in different parts of India as improved pure line varieties [38]. Cultivar WBK-CB-14 (Coochbehar Local) is a dwarf genotype and has been cultivated as a locally-adapted genotype in sub-Himalayan foothills of Dooars region. The LR3 and LR4 are two induced mutant lines, developed through
300 and 350 Gy gamma radiation of seeds of var. PUSA-902 and var. WBK-CB-14, respectively, and have been isolated as $\mathrm{NaCl}$-tolerant mutant lines in grass pea [39]. Fresh and healthy seeds with uniform size and from last season harvest (winter of 2011-2012) were collected from Pulses and Oilseeds Research Station, Berhampur $\left(24.1^{\circ} \mathrm{N}, 88.25^{\circ} \mathrm{E}\right)$, West Bengal, India. Fresh seeds from $\mathrm{M}_{2}$ generation harvest of LR3 and LR4 mutant lines were collected separately and used in the present study.

2.2. Treatment Protocol and Plant Growth. 20 dry, healthy, and uniform-sized seeds genotype ${ }^{-1}$ treatment $^{-1}$ were surface sterilized in $70 \%$ ethanol for $2 \mathrm{~min}$, rinsed twice in deionized water, and then placed on water-moistened filter papers in Petri dishes in an incubator at $25^{\circ} \mathrm{C}$ with $12 \mathrm{~h}$ light following the guidelines of ISTA [40]. Germinated seeds were immediately transferred to twelve inches earthen pots containing a mixture (total amount of $6.5 \mathrm{Kg}$ ) of this soil, vermiculite, and farmyard manure $(1: 1: 1)$. The experimental soil was clay loam in texture (clay $32.67 \%$, silt $49.22 \%$, and sand $18.11 \%$ ) and neutral $(\mathrm{pH} 7.0)$ in reaction and contained $40.7 \mathrm{mg} \mathrm{kg}^{-1}$ exchangeable $\mathrm{Na}$ and $7.39 \mathrm{mg} \mathrm{kg}^{-1}$ water exchangeable $\mathrm{Cl}$. Seedlings were thinned to two per pot after emergence and watered evenly for their uniform growth until 7 days after first emergence. The pots were kept under control condition (temperature $20^{\circ} \mathrm{C}-27^{\circ} \mathrm{C}$, humidity of $70-77 \%$, neutral light intensity $330-400 \mu \mathrm{mol} \mathrm{m}^{-2} \mathrm{~s}^{-1}$ ) during October-December. Salt treatment commenced on 20-day-old seedlings. The control plants from each of the six genotypes were irrigated with distilled water, while others were subjected to salinity stress by watering them with $150 \mathrm{mM} \mathrm{NaCl}$-supplemented distilled water $(300 \mathrm{~mL}$ water in each pot), respectively, thrice a week. Five pots (two plants pot $^{-1}$ ) genotype $e^{-1}$ were arranged in a randomized complete block design with five replications of each treatment. Salt concentration of $150 \mathrm{mM}$ was found critical in an earlier study for determining tolerance level of grass pea genotypes to salt stress [41] and, thus, was selected for the present study. Salt concentration in pot soil was regularly checked by measuring electrical conductivity with a conductivitimeter (Systronics M-308, Kolkata, India), and evapotranspirational losses were compensated daily with deionized water. Each of the six control plants exhibited nonsignificant $(P>0.05)$ variations for the traits studied, and therefore mean of all controls was presented for comparison with treated genotypes.

2.3. Growth Measurements. Plants were harvested at 15, 30, and 60 days after the commencement of salt treatments (DAC) and separated into roots and shoots. Plant height $(\mathrm{cm})$ and number of primary branches were recorded at harvest. To determine dry weights, plants were separated into roots and shoots. Roots were washed in tap water to remove soil and rinsed in de-ionised water. Plant materials were oven-dried at $65^{\circ} \mathrm{C}$ for $48 \mathrm{~h}$ and weighed. Fully expanded leaf samples from primary branches of plants were used for analysis of leaf biochemical parameters and antioxidant defense response. 
2.4. Measurement of Chlorophyll and Carotenoids Contents and Rates of Photosynthesis. Leaf chlorophyll and carotenoid contents were determined by the method of Lichtenthaler [42]. Leaf tissue $(50 \mathrm{mg})$ was homogenized in $10 \mathrm{~mL}$ chilled acetone $(80 \%)$. The homogenate was centrifuged at $4,000 \times \mathrm{g}$ for $12 \mathrm{~min}$. Absorbance of the supernatant was recorded at 663, 647 and $470 \mathrm{~nm}$ for chlorophyll $a$, chlorophyll $b$ and carotenoids, respectively. The contents were expressed as $\mathrm{mg}$ chlorophyll or carotenoids $\mathrm{g}^{-1} \mathrm{FW}$. The chlorophyll stability indices (CSI\%) were measured using the following formula: (Total chlorophyll content in stressed leaves/total chlorophyll content in control leaves) $\times 100$. Leaf photosynthetic rate was assayed following the methods of Coombs et al. [43] using a portable photosynthesis system (LI-6400XT, LI-COR, USA).

2.5. Estimation of $\mathrm{Na}^{+}$and $\mathrm{K}^{+}$Contents. Fully expanded leaves of control and salt-treated plants were analysed for total $\mathrm{Na}^{+}$and $\mathrm{K}^{+}$contents following the method of Kumar and Sharma [44]. The oven-dried leaf $(0.2 \mathrm{~g})$ was ground to fine powder and transferred to a digestion flask $(50 \mathrm{~mL})$ containing acid mixture $(3 \mathrm{~mL})$ of concentrated $\mathrm{H}_{2} \mathrm{SO}_{4}$ and $\mathrm{HClO}_{4}$ in the ratio of $9: 1(\mathrm{v} / \mathrm{v})$. The flask was heated gently over a hot plate for 10 to $12 \mathrm{~min}$ until the solution became colorless. The cooled digest was then diluted by adding double distilled water and volume was made up as required. The estimation of $\mathrm{Na}^{+}$and $\mathrm{K}^{+}$contents in acid extracts was carried out using an atomic absorption spectrophotometer (Perkin Elmer, AA-100).

2.6. Determination of Leaf Proline Level. Leaf proline content was estimated according to the method of Bates et al. [45] from fully expanded leaf samples collected from first formed primary branches on respective harvest dates $(20,40$, and 60 DAS).

2.7. Analysis of $\mathrm{H}_{2} \mathrm{O}_{2}$ Content. Fresh tissue of $0.1 \mathrm{~g}$ was powdered and blended with $3 \mathrm{~mL}$ acetone for $30 \mathrm{~min}$ at $4^{\circ} \mathrm{C}$. Then the sample was filtered through eight layers of gauze cloth. After addition of $0.15 \mathrm{~g}$ active carbon, the sample was centrifuged twice at $3,000 \times \mathrm{g}$ for $20 \mathrm{~min}$ at $4^{\circ} \mathrm{C}$ and then $0.2 \mathrm{~mL} 20 \% \mathrm{TiCl}_{4}$ in $\mathrm{HCl}$ and $0.2 \mathrm{~mL}$ ammonia was added to $1 \mathrm{~mL}$ of the supernatant. After reaction, the compound was centrifuged at $3,000 \times \mathrm{g}$ for $10 \mathrm{~min}$, the supernatant was discarded, and the pellet was dissolved in $3 \mathrm{~mL}$ of $1 \mathrm{M} \mathrm{H}_{2} \mathrm{SO}_{4}$ and absorbance was measured at $410 \mathrm{~nm} . \mathrm{H}_{2} \mathrm{O}_{2}$ content was measured from the absorbance at $410 \mathrm{~nm}$ using a standard curve, following the methods of Wang et al. [46].

2.8. Estimation of Lipid Peroxidation. Lipid peroxidation rates were determined by measuring the malondialdehyde (MDA) equivalents following the method of Hodges et al. [47]. About $0.5 \mathrm{~g}$ of fresh tissue was homogenized in a mortar with $80 \%$ ethanol. The homogenate was centrifuged at $3,000 \times \mathrm{g}$ for $12 \mathrm{~min}$ at $4^{\circ} \mathrm{C}$. The pellet was extracted twice with the same solvent. The supernatants were pooled and $1 \mathrm{~mL}$ of this sample was added to a test tube with an equal volume of either the solution comprised of 20\% TCA and $0.01 \%$ butylated hydroxy toluene (BHT) or solution of $20 \%$ TCA,
$0.01 \%$ BHT, and $0.65 \%$ TBA. Samples were heated at $95^{\circ} \mathrm{C}$ for $25 \mathrm{~min}$ and cooled to room temperature. Absorbance was measured at 450, 532, and $600 \mathrm{~nm}$. Level of lipid peroxides was calculated following Hodges et al. [47] and expressed as nmol MDA g ${ }^{-1} \mathrm{FW}$.

2.9. Assay of Electrolyte Leakage. Electrolyte leakage (EL) was assayed by measuring the ions leaching from tissue into deionised water [39]. Fresh samples $(100 \mathrm{mg})$ were cut into small pieces (about $5 \mathrm{~mm}$ segments) and placed in test tubes containing $10 \mathrm{~mL}$ deionised water. Tubes were kept in a water bath at $32^{\circ} \mathrm{C}$ for $2 \mathrm{~h}$. After incubation, electrical conductivity $\left(\mathrm{EC}_{1}\right)$ of the bathing solution was recorded with an electrical conductivity meter (Systronics M-308, Kolkata, India). The samples were then autoclaved at $121^{\circ} \mathrm{C}$ for $20 \mathrm{~min}$ to completely kill the tissues and release all electrolytes. Samples were then cooled to $25^{\circ} \mathrm{C}$ and final electrical conductivity $\left(\mathrm{EC}_{2}\right)$ was determined. The $\mathrm{EL}$ was expressed as a percentage by the formula $(\mathrm{EL} \%)=\left(\mathrm{EC}_{1}\right) /\left(\mathrm{EC}_{2}\right) \times 100$.

2.10. Estimation of Foliar Ascorbic Acid. Reduced AsA and oxidized ascorbate (DHA) contents were determined by the method of Law et al. [48]. AsA redox was calculated as AsA/(AsA + DHA).

2.11. Antioxidant Enzyme Assays. Fresh leaf tissue of $250 \mathrm{mg}$ was homogenized in $1 \mathrm{~mL}$ of $50 \mathrm{mM}$ potassium phosphate buffer ( $\mathrm{pH} 7.8$ ) containing $1 \mathrm{mM}$ EDTA, $1 \mathrm{mM}$ dithiotreitol, and $2 \%(\mathrm{w} / \mathrm{v})$ polyvinylpyrrolidone (PVP) using a chilled mortar and pestle kept in an ice bath. The homogenate was centrifuged at $15,000 \times \mathrm{g}$ at $4^{\circ} \mathrm{C}$ for $20 \mathrm{~min}$. Clear supernatant was used for enzyme assays. For measuring APX (EC 1.11.1.11) activity, the tissue was separately ground in homogenizing medium containing $2.0 \mathrm{mM}$ AsA in addition to the other ingredients. All assays were done at $25^{\circ} \mathrm{C}$. Soluble protein content was determined according to Bradford [49] using BSA as a standard.

SOD (EC 1.15.1.1) activity was determined by nitro blue tetrazolium (NBT) photochemical assay following Beyer and Fridovich [50]. In this method, $1 \mathrm{~mL}$ of solution containing $50 \mathrm{mM}$ potassium phosphate buffer $(\mathrm{pH} 7.8), 9.9 \mathrm{mM} \mathrm{L}-$ methionine, $57 \mu \mathrm{M}$ NBT, and $0.025 \%$ triton-X-100 were added into small glass tubes followed by $20 \mu \mathrm{L}$ of enzyme extract. Reaction was started by adding $10 \mu \mathrm{L}$ of riboflavin solution $\left(0.044 \mathrm{mg} \mathrm{mL}^{-1}\right)$ and placing the tubes in an aluminium foil-lined box having two $20 \mathrm{~W}$ fluorescent lamps for $7 \mathrm{~min}$. A parallel control was run where buffer was used instead of sample. After illumination, the absorbance of solution was measured at $560 \mathrm{~nm}$. A nonirradiated complete reaction mixture served as a blank. SOD activity was expressed as $\mathrm{U}$ (unit) $\mathrm{min}^{-1} \mathrm{mg}^{-1}$ protein. One unit of SOD was equal to that amount which causes a $50 \%$ decrease of SOD-inhibited NBT reduction. SOD isozymes were individualized by native PAGE on $10 \%$ acrylamide gel and were localized by a photochemical method [50]. Activity staining gels were incubated for $30 \mathrm{~min}$ in $50 \mathrm{mM} \mathrm{K}$-phosphate buffer, $\mathrm{pH} 7.5$, containing $2 \mathrm{mM} \mathrm{KCN}$ or $5 \mathrm{mM} \mathrm{H}_{2} \mathrm{O}_{2}$. Cu/Zn-SOD is inhibited by both $\mathrm{KCN}$ and $\mathrm{H}_{2} \mathrm{O}_{2}$; Fe SOD is inactivated by 
$\mathrm{H}_{2} \mathrm{O}_{2}$ but resistant to $\mathrm{KCN}$, and $\mathrm{Mn} \mathrm{SOD}$ is resistant to both inhibitors.

APX activity was assayed following methods adopted by Nakano and Asada [51]. Three milliliters of the reaction mixture contained $50 \mathrm{mM}$ K-phosphate buffer ( $\mathrm{pH} 7.0$ ),

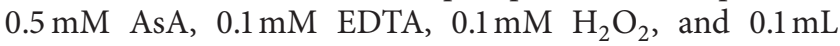
enzyme extract. The $\mathrm{H}_{2} \mathrm{O}_{2}$-dependent oxidation of AsA was followed by a decrease in the absorbance at $290 \mathrm{~nm}(\varepsilon=$ $\left.2.8 \mathrm{mM}^{-1} \mathrm{~cm}^{-1}\right)$. APX activity was expressed as nmol AsA oxidized $\mathrm{min}^{-1} \mathrm{mg}^{-1}$ protein. Native PAGE of APX isozymes was performed in $4 \%$ gel and stained following Mittler and Zilinskas [52] based on the inhibition of NBT reduction by AsA.

CAT (EC 1.11.1.6) activity was measured according to Chance and Maehly [53] with slight modifications. Enzymatic activity was initiated by adding $50 \mu \mathrm{L}$ of enzyme extract into the reaction mixture containing $500 \mu \mathrm{L}$ of $\mathrm{K}-1(0.1 \mathrm{M}, \mathrm{pH}$ 6.5), $250 \mu \mathrm{L}$ of distilled water, and $200 \mu \mathrm{L}$ of $75 \mathrm{mM} \mathrm{H}_{2} \mathrm{O}_{2}$. CAT activity was monitored at $240 \mathrm{~nm}$ for $2 \mathrm{~min}$ at $25^{\circ} \mathrm{C}$ after initiation of the reaction and was measured against a blank reaction mixture containing no enzyme extract. CAT specific activity ( $\mathrm{nmol} \mathrm{H}_{2} \mathrm{O}_{2}$ degraded $\mathrm{min}^{-1} \mathrm{mg}^{-1}$ protein) was calculated using the molar absorptivity of $43.6 \mathrm{M}^{-1} \mathrm{~cm}^{-1}$ for $\mathrm{H}_{2} \mathrm{O}_{2}$ at $240 \mathrm{~nm}$. CAT isozyme profiling was done on $6 \%$ acrylamide gel, following Woodbury et al. [54].

2.12. Statistical Analyses. The results presented here are the mean values \pm standard error (SE) of at least five replicates. Means were compared by ANOVA using the SPSS v. 10 (SPS Inc, USA) and evaluated using Duncan's Multiple Range Test at $P \leq 0.05$.

\section{Results}

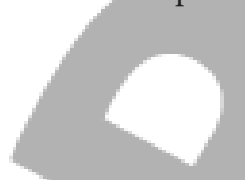

3.1. Effect of Salt Stress on Growth. Six grass pea genotypes subjected to $\mathrm{NaCl}$-treatment $(150 \mathrm{mM})$ exhibited significant $(P<0.05)$ variations among themselves for growth parameters. While 15 DAC represented early vegetative growth, 30 DAC denoted flowering stage and 60 DAC reflected pod-bearing stage. Plant height, length of internodes, primary branches/plant, and shoot and root dry weight were decreased significantly compared to those of control in all six genotypes with significantly different magnitudes at 15 DAC (Figures 1(a)-1(e)) and were further reduced in var. PUSA90-2 and WBK-CB-14 at 30 DAC. Shoot dry weight in saline versus control plants was reduced by about 2-3-fold at 15 DAC with higher magnitude in PUSA-90-2 and WBK-CB14 than B1 (2.7-fold), BioL-212 (2.5-fold), LR3 (2.2-fold) and LR4 (2-fold). Similar trend was noticed in case of root dry weight. Nearly 4-fold reduction in biomass production (total dry weight) was measured in PUSA-90-2 and WBK-CB-14 at 30 DAC. Growth traits plummeted to lowest level in PUSA90-2 and WBK-CB-14 at 60 DAC with 5-5.5 reduction in relation to control. By contrast, nearly normal plant height, primary branches and biomass production were noticed in the rest four genotypes at 60 DAC (Figures 1(a)-1(e)).
3.2. Photosynthetic Apparatus, CSI\%, and Photosynthesis. Significant variation was observed among six genotypes regarding pigment composition during progression of $\mathrm{NaCl}$ treatment. Within photosynthetic apparatus, chl a content was changed significantly (Figure 1(f)) but carotenoid content varied nonsignificantly between $1.49 \mathrm{mg} \mathrm{g}^{-1} \mathrm{FW}$ and $1.61 \mathrm{mg} \mathrm{g}^{-1} \mathrm{FW}$ among the six genotypes under $\mathrm{NaCl}$ treatment (data not shown). Compared to control plants, chl a content was measured markedly lower at 15 DAC across the genotypes but was further reduced only in PUSA-90-2 and WBK-CB-14 by 2 -fold at 30 DAC and by another 2 -fold at 60 DAC (Figure 1(f)). Chl a content was increased substantially and became quite normal in B1, BioL-212, LR3, and LR4 at 60 DAC. Chl $a / b$ ratio was also changed, accordingly. This value was significantly lower in all genotypes at $15 \mathrm{DAC}$ but was dropped to $<1$ in PUSA-90-2 and WBK-CB-14 at 30 DAC and was further reduced in these two varieties at 60 DAC (Figure 2(a)). CSI\% was 100\% in control plants but was reduced substantially across the six genotypes at $15 \mathrm{DAC}$ with severest effect on PUSA-90-2 (24.78\%) and WBK-CB$14(25.03 \%)$. It became normal in the rest four genotypes, varying $98-100 \%$ at 60 DAC. Compared to control, leaf photosynthetic rate was decreased by about 2 -fold in LR3 and LR4, 3-fold in B1, 3.3-fold in BioL-212, and nearly 4-fold in PUSA-90-2 and WBK-CB-14 till 30 DAC. Photosynthetic rate was significantly low in PUSA-90-2 and WBK-CB-14 at 60 DAC also, but it was quite normal in B1, BioL-212, LR3, and LR4 at 60 DAC (Figure 2(b)).

3.3. Salt Stress Effect on Leaf Proline Content. Compared to control (3.05-3.17 $\mu \mathrm{gg}^{-1}$ fresh weight) no significant change in leaf proline content was observed in six genotypes at 15 DAC. The content, however, was increased by about 2-fold in B1 and BioL-212 and about 3-fold in the two mutant lines at 30 DAC. Proline level remained normal in PUSA-90-2 and WBK-CB-14 and it continued till 60 DAC (data not shown).

3.4. Effect on Leaf $\mathrm{Na}^{+}$and $\mathrm{K}^{+}$Ions. Changes in leaf $\mathrm{Na}^{+}$ and $\mathrm{K}^{+}$content were significant $(P<0.05)$ across six genotypes (Figures 3(a) and 3(b)). This was due to significant accumulation of $\mathrm{Na}^{+}$and reduction of $\mathrm{K}^{+}$concentration in all six genotypes at 15 DAC and in PUSA-90-2 and WBKCB-14 at 30 DAC and 60 DAC. Compared to control, $\mathrm{Na}^{+}$ concentration was markedly decreased while $\mathrm{K}^{+}$was considerably enhanced in B1, BioL-212, LR3, and LR4 genotypes at $30 \mathrm{DAC}$, pushing $\mathrm{K}^{+} / \mathrm{Na}^{+}$ratio significantly higher than control in B1 and BioL-212 and close to normal level in both mutant lines at $30 \mathrm{DAC}$. It was nonsignificantly changed at 60 DAC (Figure 3(c)).

3.5. As-Induced $\mathrm{H}_{2} \mathrm{O}_{2}$ Accumulation, Lipid Peroxidation, and Electrolyte Leakage (EL\%). Compared to control, accumulation of $\mathrm{H}_{2} \mathrm{O}_{2}$ and MDA was significantly higher in B1, BioL212, LR 3, and LR4 at 15 DAC but was significantly different in different genotypes (Figures $4(\mathrm{a})-4(\mathrm{c})$ ). The increase of $\mathrm{H}_{2} \mathrm{O}_{2}$ was 3.5-4.5-fold while MDA level was increased by about 3-fold across the four genotypes at 15 DAC. Statistically significant rise was also observed for EL\% (Figure 4(c)). By 


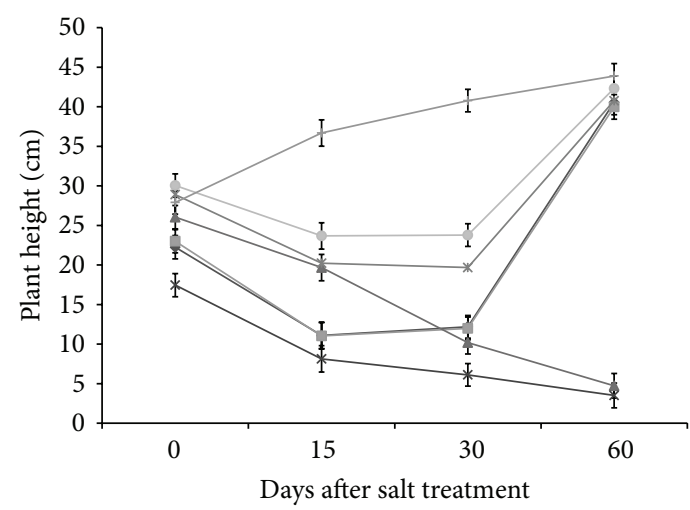

(a)

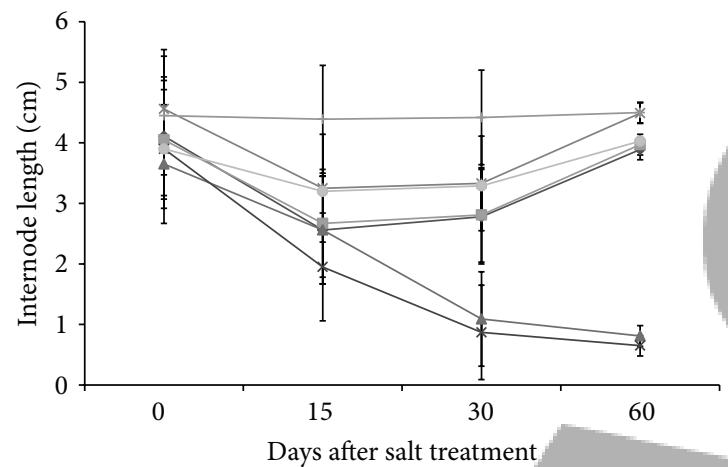

(c)

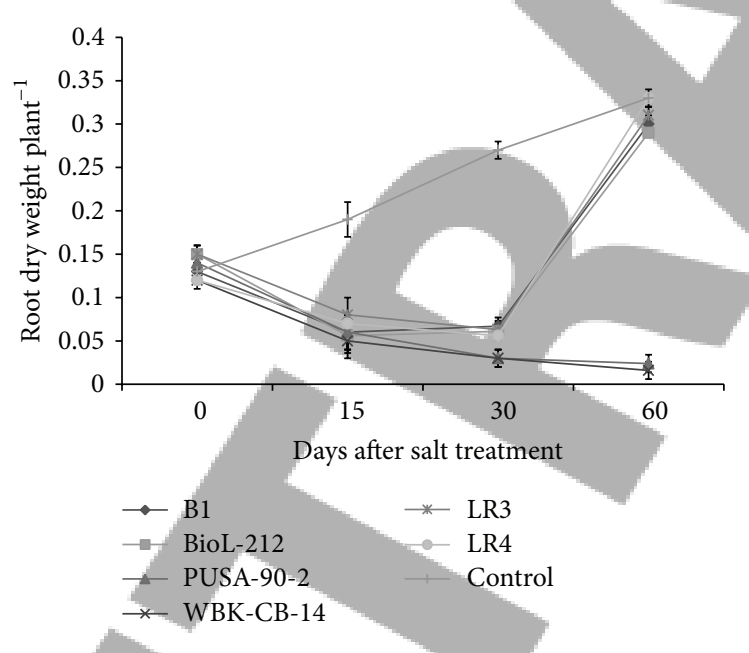

(e)

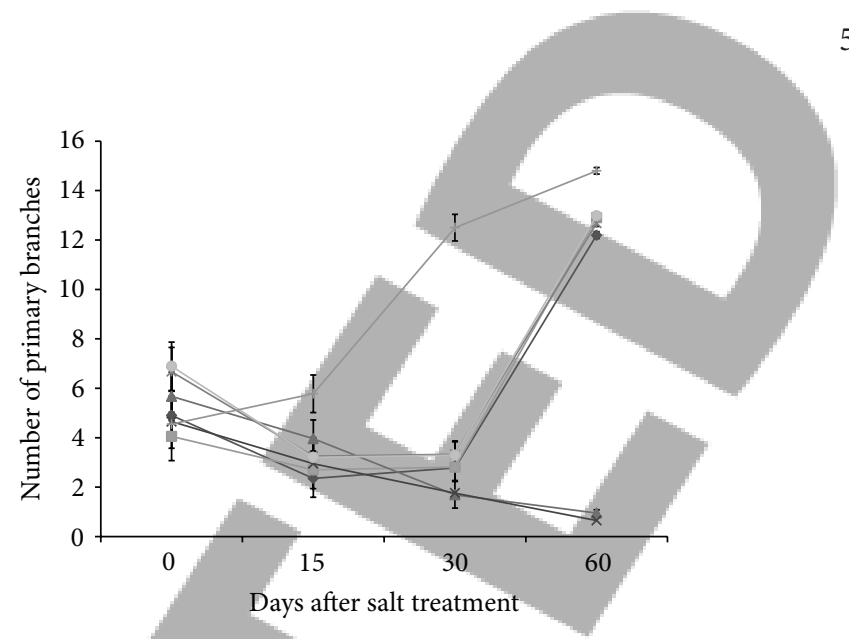

(b)

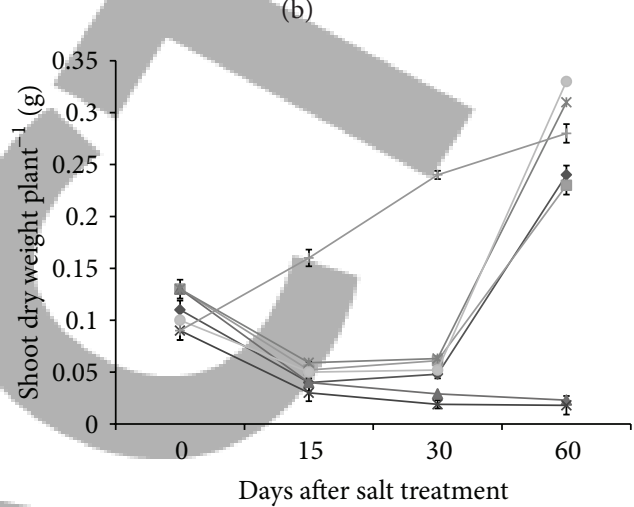

(d)

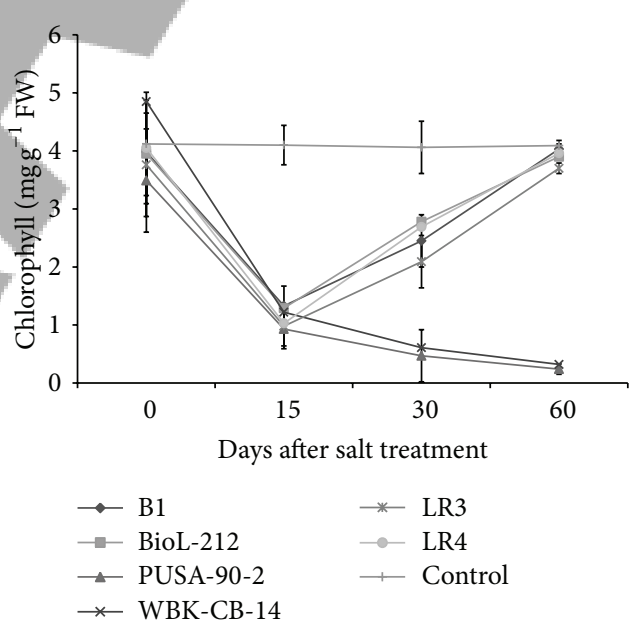

(f)

FIGURE 1: Changes in (a) plant height, (b) primary branches/plant, (c) internode length, (d) shoot dry weight (g), (e) root dry weight (g), and (f) chlorophyll $a$ content in B1, BioL-212, PUSA-90-2, WBK-CB-14, LR3, and LR4 along with mean control value of grass pea (Lathyrus sativus L.) at 15,30 , and 60 days after salt $(150 \mathrm{mM} \mathrm{NaCl})$ treatment. Data are means $\pm \mathrm{SE}$ of four replicates. Means of respective genotypes with different small letters are significantly different at $P \leq 0.05$ by ANOVA followed by Duncan's Multiple Range Test. The control of each of the six genotypes being without any significant differences $(P>0.05)$ among themselves; mean value of all controls was presented.

contrast, $\mathrm{H}_{2} \mathrm{O}_{2}$ content was markedly low but MDA content and EL\% was quite high in PUSA-90-2 and WBK-CB-14 at 15 DAC. At 30 DAC, $\mathrm{H}_{2} \mathrm{O}_{2}$-level was decreased by about 2-2.2fold in B1, BioL-212, LR3, and LR4 from the level recorded at 15 DAC, but the content was still significantly higher than that in control (Figure 4(a)). MDA content and EL\%, however, 


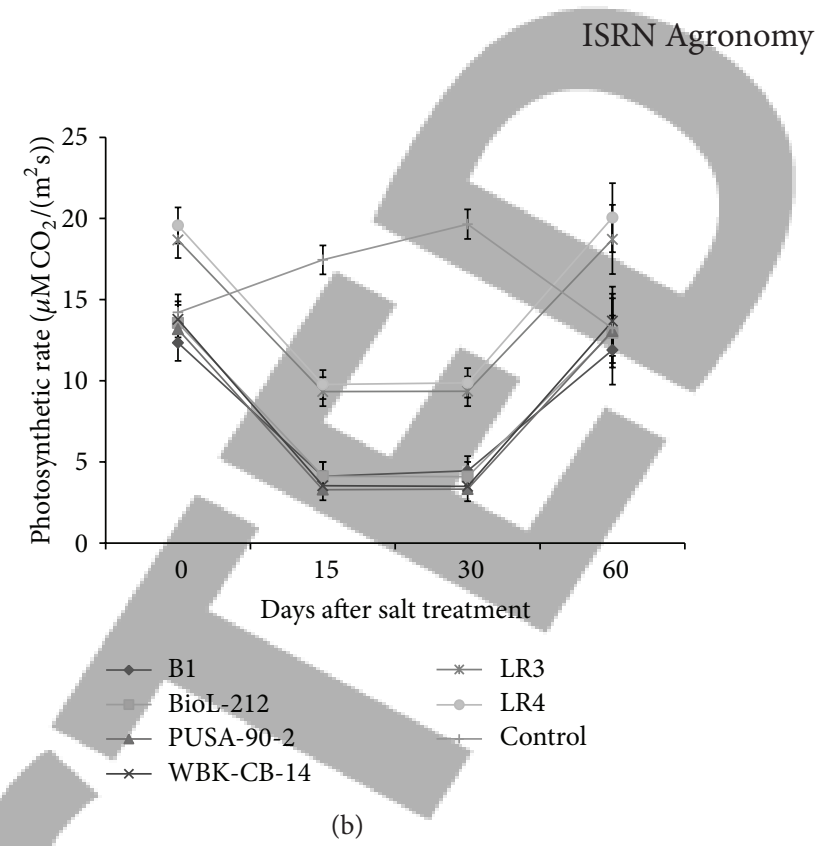

(a)

(b)

FIGURE 2: Effects of salt treatment $(150 \mathrm{mM} \mathrm{NaCl})$ on leaf (a) chlorophyll (chl) $a / b$ ratio and (b) photosynthesis in six grass pea genotypes along with mean control value at 15, 30, and 60 days after treatment. Data are means \pm SE of four replicates. Means of respective genotypes with different small letters are significantly different at $P \leq 0.05$ by ANOVA followed by Duncan's Multiple Range Test. The control of each of the six genotypes being without any significant differences $(P>0.05)$ among themselves; mean value of all controls was presented.

3.6. Antioxidant Defense Responses to NaCL-Treatment. Reduced ascorbate (AsA) content as well as AsA-redox was significantly lower in all six genotypes at 15 DAC (Table 1). At 30 DAC, AsA content was increased considerably from its 15 DAC level in B1, BioL-212, LR3, and LR 4 genotypes and became normal (Table 1). Further increase in AsA level was measured in these four genotypes at $60 \mathrm{DAC}$. AsA level and its redox state were the highest in LR4, followed by BioL-212, LR3 and then by B1 at 60 DAC (Table 1). AsA content and AsA-redox was significantly lower in PUSA-90-2 and WBKCB-14 cultivars during 30 and 60 DAC (Table 1).

Among the $\mathrm{H}_{2} \mathrm{O}_{2}$-metabolizing enzymes, statistically significant higher SOD activity over the control was observed in B1, BioL-212, LR3, and LR4 seedlings since 15 DAC and the trend was continued till 60 DAC (Table 1). Compared to control, SOD activity was quite low in PUSA-90-2 (3-fold) and WBK-CB-14 (3.5-fold) at 15 DAC, but bounced back at 30 DAC registering an increase of 4-fold in PUSA-90-2 and of 6-fold in WBK-CB-14 and the level was maintained at 60 DAC (Table 1). APX activity was increased in LR3 and LR4 by about 2-2.5-fold but was quite low in B1 and BioL-212 at $15 \mathrm{DAC}$. At the same period, APX activity was normal in PUSA-90-2 and WBK-CB-14. Completely reverse situation was encountered at $30 \mathrm{DAC}$ and $60 \mathrm{DAC}$. APX activity was significantly declined in LR3, LR4, PUSA-90-2 and WBKCB-14 but was enhanced by about 2-fold in B1 and BioL212 at $30 \mathrm{DAC}$, and nonsignificant $(P>0.05)$ changes of respective values occurred at $60 \mathrm{DAC}$ (Table 1). CAT activity was markedly higher in B1 and BioL-212 and normal in PUSA-90-2 and WBK-CB-14 but was reduced substantially in LR3 and LR4 mutant lines at 15 DAC (Table 1). At 30 DAC, CAT activity was decreased significantly in B1, BioL-212, LR3, and LR4 but was increased in two mutant lines by about 23 -fold (Table 1). Similar trend was noticed at 60 DAC, also (Table 1).

3.7. In-Gel Activity of Antioxidant Enzymes Under AsExposure. Altogether five activity bands were resolved for SOD on the basis of their increasing mobility and sensitivity to $\mathrm{H}_{2} \mathrm{O}_{2}$ and $\mathrm{KCN}$ and zymograms obtained at $60 \mathrm{DAC}$ were presented (Figures 5(a) and 5(b)). Two $\mathrm{Cu} / \mathrm{Zn}$ isoforms (I and II) were consistently resolved by native PAGE in the leaf extract of control plants (Figure 5(a)). At 15 DAC, Cu/ZnSOD I and II were visualized in leaves of all the six genotypes but with much higher intensity in B1, BioL-212, LR3, and LR4 (figure not shown). At $60 \mathrm{DAC}$, in addition to $\mathrm{Cu} / \mathrm{Zn}$ I and II, two Mn -SOD isoforms (Mn SOD I and II) was distinctly visualized in PUSA-90-2 and WBK-CB-14. At the same period, one Mn SOD (Mn SOD I) in LR3 and one Fe SOD in LR4 mutant line appeared in addition to $\mathrm{Cu} / \mathrm{Zn}$ SOD I and II (Figures 5(a) and 5(b)). Similar pattern was maintained at 30 DAC in all the genotypes (Figures not presented).

For APX, a total of three isoforms (APX 1, APX 2, and APX 3) were clearly resolved in the leaf extract at 60 DAC in control and treated genotypes but at different intensity (Figure 6(a)). At 15 DAC, APX 1 was resolved as faint band in B1 and BioL-212 but along with APX 2 and APX 3 it was quite normal in the rest of the genotypes (Figure not shown). All the three isoforms were visualized as strong bands in B1 and BioL-212 at 30 DAC and 60 DAC but were diminished as faint bands in the rest of the genotypes (Figure 6(a)).

CAT activity was uniformly resolved as a single zone across the genotypes (Figure 6(b)). Band intensity was much stronger in LR3 and LR4 but was considerably lower in the 

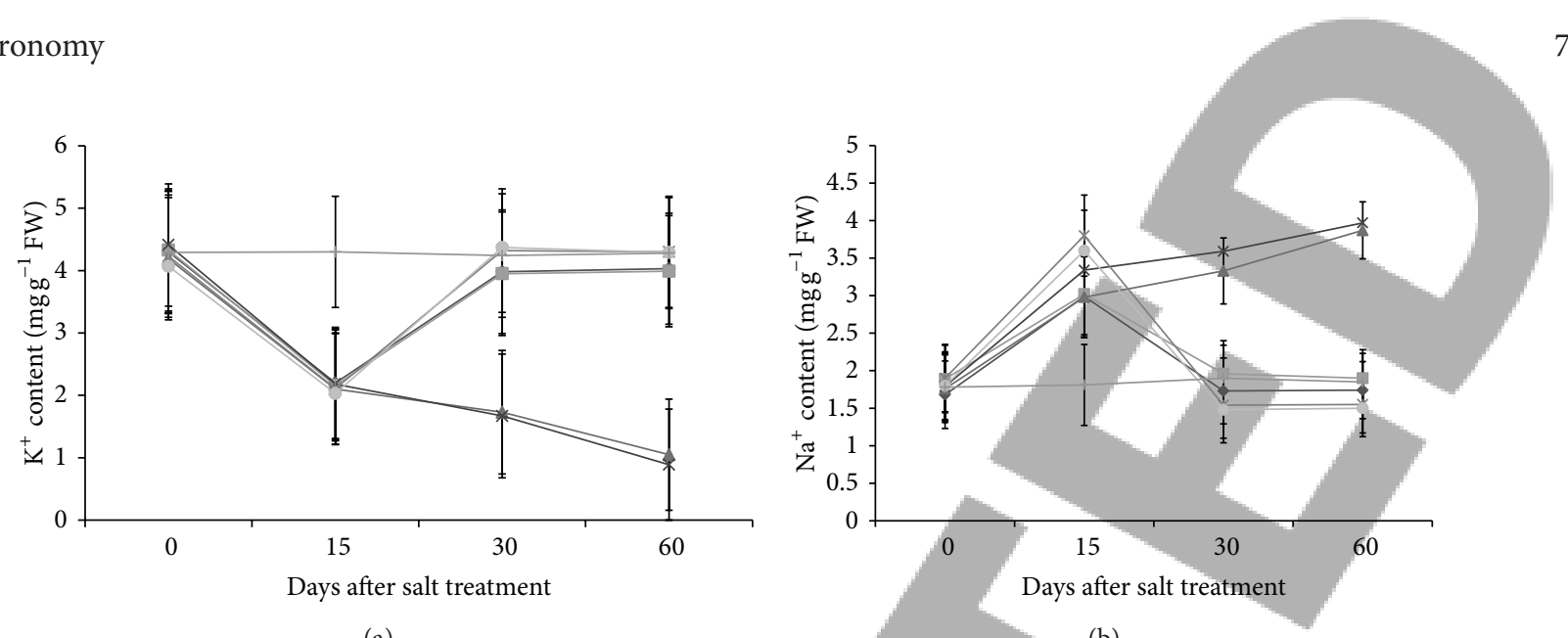

(a)

(b)

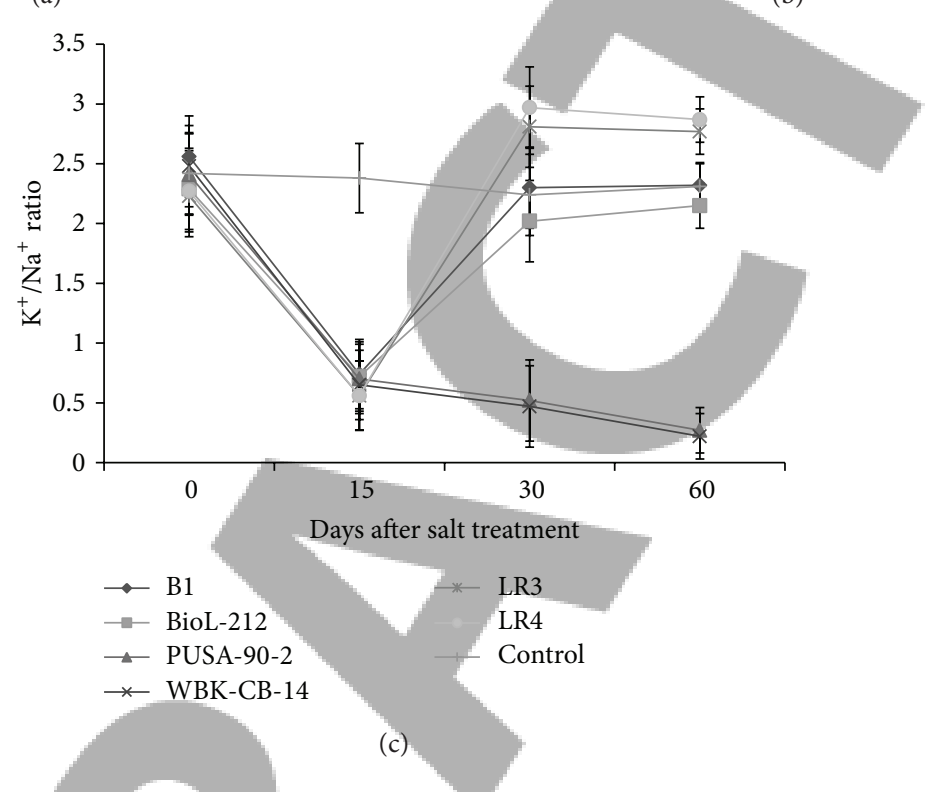

Figure 3: Changes in leaf (a) $\mathrm{K}^{+}$, (b) $\mathrm{Na}^{+}$content, and (c) $\mathrm{K}^{+} / \mathrm{Na}^{+}$ratio in six grass pea genotypes along with mean control value at 15 , 30 , and 60 days after $150 \mathrm{mM} \mathrm{NaCl}$-treatment. Data are means $\pm \mathrm{SE}$ of four replicates. Means of respective genotypes with different small letters are significantly different at $P \leq 0.05$ by ANOVA followed by Duncan's multiple range test. The control of each of the six genotypes being without any significant differences $(P>0.05)$ among themselves mean value of all controls was presented.

rest of the genotypes with faintest appearance was resolved in case of PUSA-90-2 and WBK-CB-14 genotypes at 30 and 60 DAC (Figure 6(b)). Low to moderate in-gel activity was noticed at 15 DAC (Figure not shown).

\section{Discussion}

Dry weight of plants has been considered as one of the integrative criteria in determining salt responses in plants [36]. In the present study, distinctly different response was obtained in six genotypes during progression of salt treatment. Significant reduction in plant height and primary branches might be due to marked reduction in internodes length and attributed to lower shoot dry weight in all six genotypes at $15 \mathrm{DAC}$, indicating effect of salt-treatment at early vegetative growth stages. This situation got significant twist at later stages of growth. Biomass production as measured by dry weight of shoots and roots was further reduced in var. PUSA-90-2 and WBK-CB-14 due to significantly low plant height and branches/plant at 30 DAC and 60 DAC. However, despite increase in treatment duration, growth retardation was checked in the rest four genotypes at $30 \mathrm{DAC}$, and remarkably enough, growth traits bounced back to normal in these four genotypes at 60 DAC. Results illustrated that the greatest reduction in plant growth occurred during the first period of salt treatment (vegetative growth stage) in cases of B1, BioL-212, LR3, and LR4 but it was extended to its severest inhibitory effect on growth of PUSA-90-2 and WBK-CB-14 at later stages (reproductive) of growth. The normal (control like) dry matter production in four genotypes at flowering stage (30 DAC) and its maintenance up to pod-bearing stage (60 DAC) despite initial blow at 15 DAC was unique in grass pea and strongly suggested effective prevention of early $\mathrm{NaCl}$-stress at reproductive period to maintain salinitytolerance in the present experimental conditions. A good positive correlation between plant height $(r=0.95, n=$ 10) as well as primary branches/plant $(r=0.78, n=10)$ and shoot dry weight was indicative that salt tolerance was 

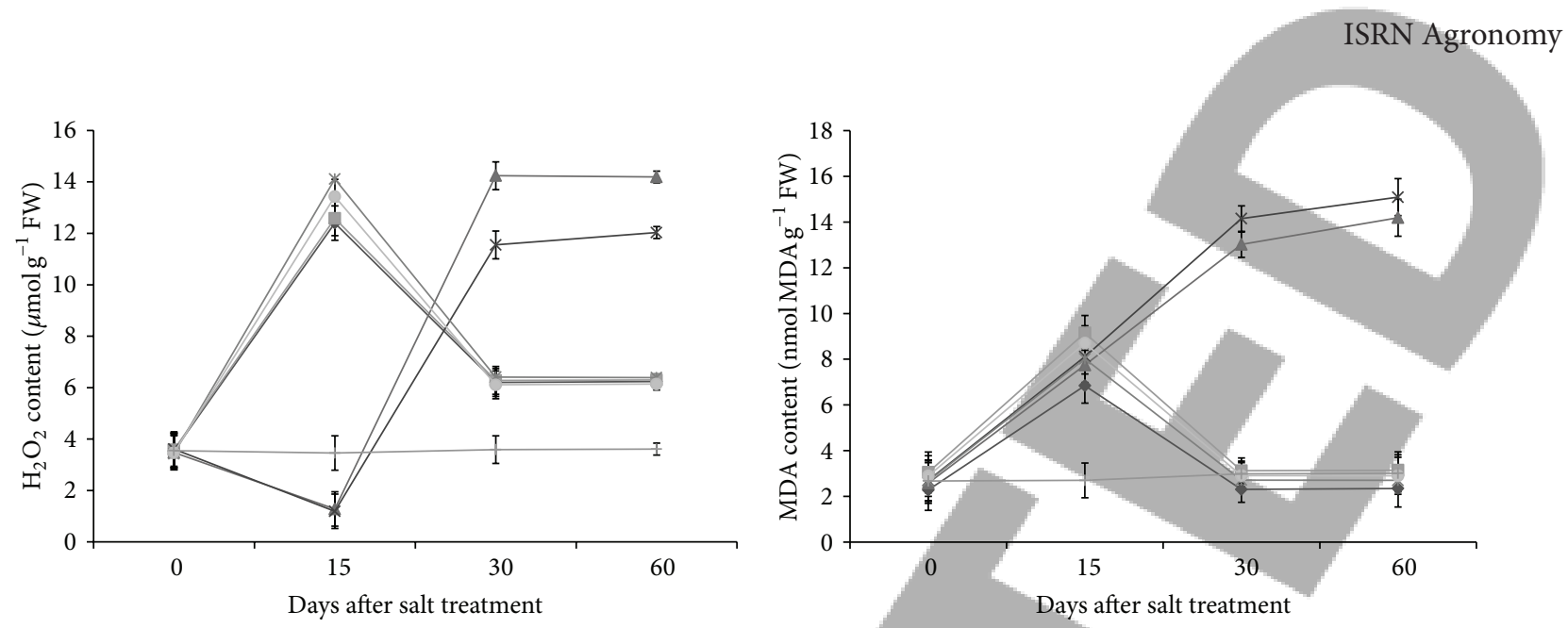

(a)

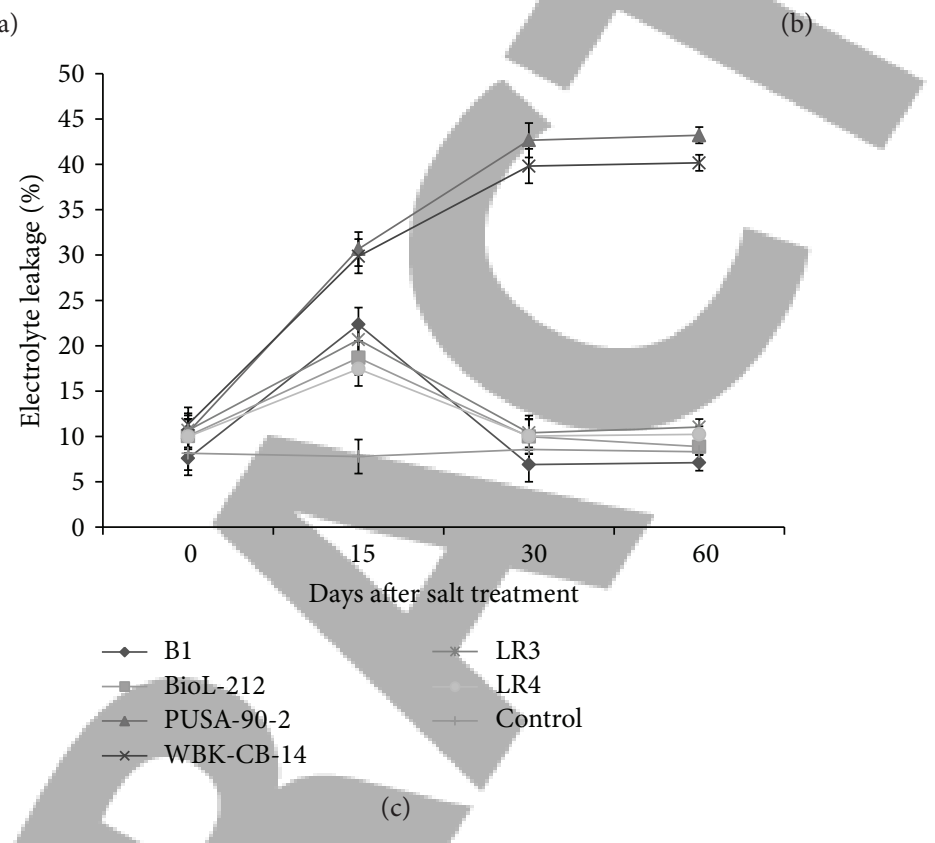

FIGURE 4: Changes in foliar (a) accumulation of $\mathrm{H}_{2} \mathrm{O}_{2}$, (b) malondialdehyde (MDA) content, and (c) electrolyte leakage \% in six grass pea genotypes along with mean control value at 15, 30, and 60 days after $150 \mathrm{mM} \mathrm{NaCl}$-treatment. Data are means \pm SE of four replicates. Means of respective genotypes with different small letters are significantly different at $P \leq 0.05$ by ANOVA followed by Duncan's multiple range test. The control of each of the six genotypes being without any significant differences $(P>0.05)$ among themselves, mean value of all controls was presented.

positively associated with normal plant dry weight, which was increased by positive contribution from other components, least affected by salt induced injury in tolerant lines. In grass pea, high tolerance of dwf1 and dwf 2 dwarf mutant lines to $170 \mathrm{mM} \mathrm{NaCl}$-treatment was indicated by their normal (control like) plant dry weight, while low plant biomass accumulation in the third dwarf line, dwf3, was associated with symptoms of increased salt sensitivity [55]. Reduction in plant dry weight under high salt treatment was reported in pea, grass pea, Phaseolus and lentil $[1,35,41,56,57]$ while increasing dry weight over control was reported in grass pea mutant lines showing high tolerance to salinity stress [39].

The toxic effect of salt inside the plant triggers the "phase II" response of growth, and the most affected organ is leaf [36]. Changes in plant biomass production under salinity may be due to many reasons such as lack of maintenance of turgor, sodium/chloride ion toxicity and disturbances in metabolic pathways. Since these factors disturb the functioning of gas exchange attributes they ultimately lead to a decline in activity of photosynthetic apparatus $[5,57]$. In the present study, reduction in chl a content was mainly responsible for decrease in chl $a / b$ ratio, suggesting $\mathrm{NaCl}$-induced disruption in photosynthetic apparatus of all six genotypes at early stages of growth. The magnitude of this disruption was also manifested by markedly low chlorophyll stability index, consequently resulting in low rate of photosynthesis in salt-affected genotypes. This situation were significantly improved at later stages of growth in B1, BioL-212, LR3, and LR4 with normal chl $a / b$ ratio, chlorophyll stability and normal (control like) rate of photosynthesis, as the marks of salt-tolerance. Contrastingly, significant reduction in all these parameters in PUSA-90-2 and WBK-CB-14 at 30 


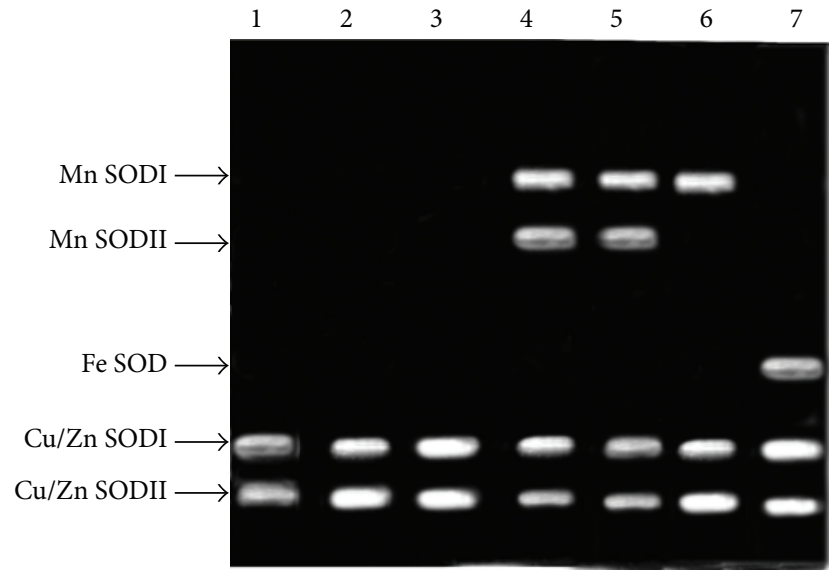

(a)

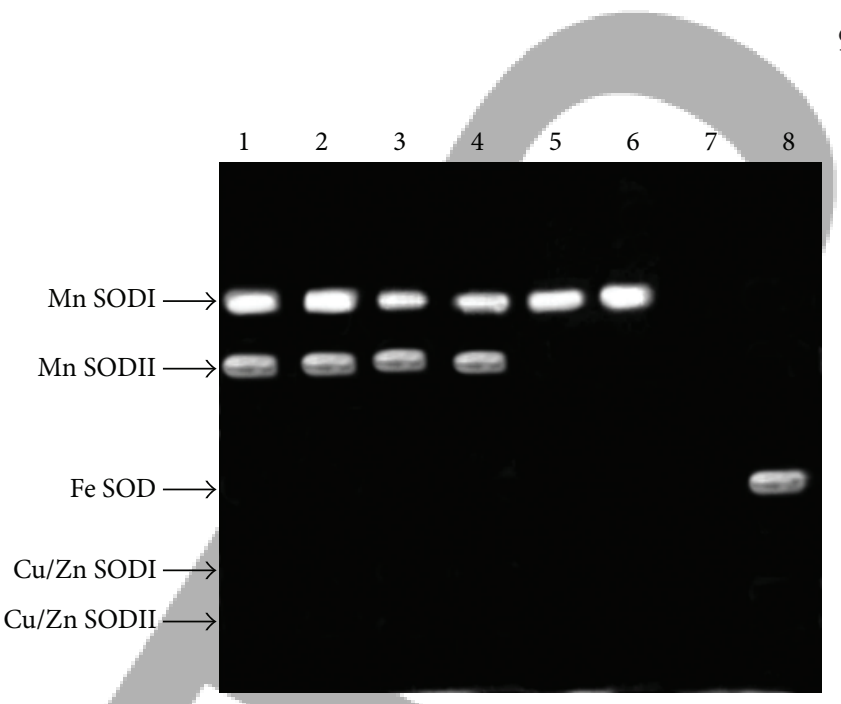

$\mathrm{H}_{2} \mathrm{O}_{2}$ KCN $\mathrm{H}_{2} \mathrm{O}_{2}$ KCN $\mathrm{H}_{2} \mathrm{O}_{2} \quad \mathrm{KCN} \mathrm{H}_{2} \mathrm{O}_{2}$ KCN

FIGURE 5: (a) Activity gel of superoxide dismutase (SOD) in native PAGE on 10\% acrylamide gels of leaf extracts of six grass pea (Lathyrus sativus L.) genotypes at 60 days after commencement of $150 \mathrm{mM} \mathrm{NaCl}$-treatment; Lane 1-control plants (Cu/Zn SOD I and II), lane 2variety B1 (Cu/Zn SOD I and II), lane 3-variety BioL-212 (Cu/Zn SOD I and II), lane 4-PUSA-90-2 (Mn SOD I and II, Cu/Zn SOD I and II), lane 5-WBK-CB-14 (Mn SOD I and II, Cu/Zn SOD I and II), lane 6-LR3 mutant (Mn SOD I, Cu/Zn SOD I and II), and lane 7-LR4 mutant (Fe SOD, Cu/Zn SOD I and II), and (b) inhibitor studies with $\mathrm{H}_{2} \mathrm{O}_{2}$ and $\mathrm{KCN}$ and visualization of SOD isoforms in native PAGE of leaf extracts of grass pea (Lathyrus sativus L.) variety PUSA-90-2 (lanes 1 and 2), WBK-CB-14 (lanes 3 and 4), LR3 mutant (lanes 5 and 6), and LR 4 mutant (lanes 7 and 8) at 60 days after commencement of salt treatment. The control plants, variety B1 and BioL-212 containing only $\mathrm{Cu} / \mathrm{Zn}$ SOD I and II showed no bands in inhibitor study and thus not presented.

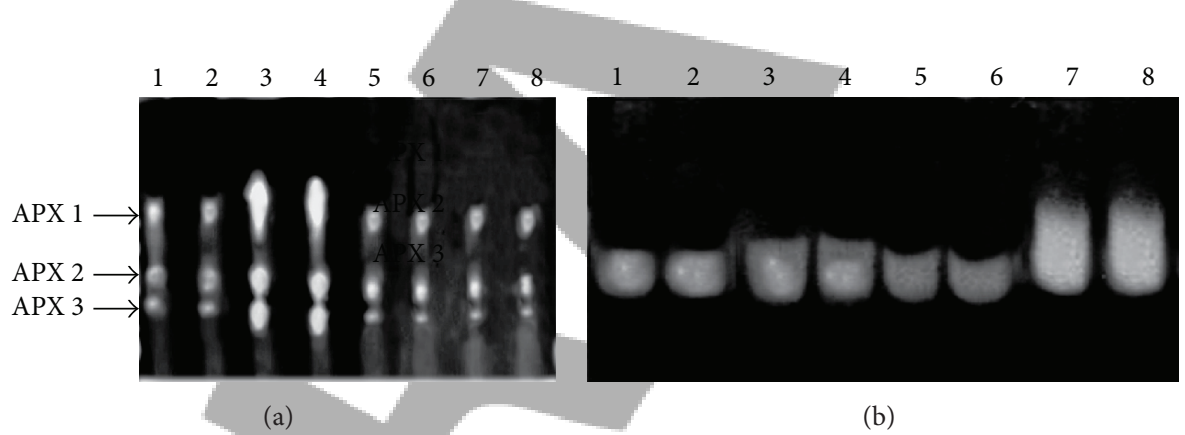

FIGURE 6: Effects of $150 \mathrm{mM} \mathrm{NaCl}$-treatments on isozymes banding of (a) APX activity in native PAGE on 4\% acrylamide gels of leaf extracts of grass pea (Lathyrus sativus L.) genotypes at 60 days after commencement of treatment: lanes 1 and 2-control plant, lane 3-variety B1, lane 4-BioL-212, lane 5-PUSA-90-2, lane 6-WBK-CB-14, lane 7-LR3 mutant and lane 8-LR4 mutant: (b) CAT activity in native PAGE on $6 \%$ acrylamide gels of leaf extracts of grass pea (Lathyrus sativus L.) genotypes at 60 days after commencement of treatment; lanes 1 and 2-control plants, lane 3-variety B1, lane 4-BioL-212, lane 5-PUSA-90-2, lane 6-WBK-CB-14, lane 7-LR3, and lane 8-LR4 mutant.

DAC and at 60 DAC severely impeded plant photosynthesis at reproductive stage which might be instrumental in low biomass production in these two genotypes. This is despite the fact that chl $b$ and carotenoids were quite normal (control like) throughout the treatment period. Carotenoid has been regarded as a primary nonenzymatic antioxidant defense components protecting plants from adverse effect of ROS generated under $\mathrm{NaCl}$-induced oxidative stress in plants including legumes [5]. Increase in $\operatorname{chl} a$ and $b$ and carotenoid content, however, was observed in grass pea genotypes and mutant lines exhibiting tolerance to salt treatment [39, 41]. Presumably, chl a content played more vital role than chl $b$ and carotenoids in maintaining normal photosynthesis in the present genotypes under prolonged salt treatment. The reduction in chlorophyll contents could have been due to the displacement of $\mathrm{Mg}^{2+}$ by toxic $\mathrm{Na}^{+}$ions, which caused the degradation of green pigments through the disruption of ultrastructure of pigment-protein-lipid complex by ion toxicity, as explained in salt-stressed cotton plants [58]. Disruption of chlorophyll and carotenoid contents under salinity stress was also reported in Lens culinaris [56], Pisum sativum [57] and Vigna radiata [59].

Conflicting reports are available regarding specific role of proline in salt-tolerant genotypes. A positive correlation between proline over accumulation and increasing salinity/drought tolerance has been found in different crop plants including transgenics that were engineered for overproduction of proline [12]. Increase in proline content under $\mathrm{NaCl}$ stress was manifested as one of the mechanisms of salt tolerance in Lathyrus sativus [39, 41], Pisum sativum [37, 
TABLE 1: Effects of NaCl-treatments $(150 \mathrm{mM})$ on reduced ascorbate (AsA, $\left.\mu \mathrm{mol} \mathrm{g}{ }^{-1} \mathrm{FW}\right)$, redox state of ascorbate (AsA/AsA + DHA), activities of superoxide dismutase (SOD, $\mathrm{U} \mathrm{min}^{-1} \mathrm{mg}^{-1}$ protein), ascorbate peroxidase (APX, nmol AsA oxidized min ${ }^{-1} \mathrm{mg}^{-1}$ protein), and catalases (CAT, nmol $\mathrm{H}_{2} \mathrm{O}_{2}$ degraded $\mathrm{min}^{-1} \mathrm{mg}^{-1}$ protein) in leaves of control and six treated genotypes [varieies B1, BioL-212, PUSA-90-2, WBK-CB14, and two mutant lines, namely, Lathyrus resistant mutant 3 (LR3) and Lathyrus resistant mutant 4 (LR4)] at control (0) and 15, 30, and 60 days after commencement of treatment (DAC) of Lathyrus sativus L.

\begin{tabular}{|c|c|c|c|c|c|c|c|c|}
\hline Traits & $\mathrm{DAC}$ & B1 & BioL-212 & PUSA-90-2 & WBK-CB-14 & LR3 & LR4 & Mean control \\
\hline \multirow{4}{*}{ AsA } & 0 & $1.81 \pm 1.0^{\mathrm{ab}^{\prime}}$ & $1.75 \pm 1.0^{\mathrm{ab}^{\prime}}$ & $1.89 \pm 0.97^{\mathrm{aa}^{\prime}}$ & $1.79 \pm 0.89^{\mathrm{aa}^{\prime}}$ & $1.87 \pm 0.87^{\mathrm{aa}^{\prime}}$ & $1.82 \pm 0.88^{\mathrm{ab}^{\prime}}$ & $1.83 \pm 0.9^{\mathrm{aa}^{\prime}}$ \\
\hline & 15 & $1.09 \pm 0.9^{c c^{\prime}}$ & $1.08 \pm 0.8^{\mathrm{cc}^{\prime}}$ & $0.98 \pm 0.3^{\mathrm{cb}^{\prime}}$ & $1.01 \pm 0.8^{\mathrm{cb}^{\prime}}$ & $1.12 \pm 0.3^{\mathrm{bb}^{\prime}}$ & $1.03 \pm 0.8^{\mathrm{cc}^{\prime}}$ & $1.89 \pm 0.9^{\mathrm{aa}^{\prime}}$ \\
\hline & 30 & $1.80 \pm 0.3^{\mathrm{ab}^{\prime}}$ & $1.78 \pm 0.8^{\mathrm{ab}^{\prime}}$ & $0.57 \pm 0.4^{b c^{\prime}}$ & $0.73 \pm 0.2^{b c^{\prime}}$ & $1.82 \pm 0.8^{\mathrm{aa}^{\prime}}$ & $1.79 \pm 0.8^{\mathrm{ab}^{\prime}}$ & $1.75 \pm 0.9^{\mathrm{aa}^{\prime}}$ \\
\hline & 60 & $1.91 \pm 7.9^{\mathrm{ba}^{\prime}}$ & $2.28 \pm 10.0^{\mathrm{aa}^{\prime}}$ & $0.43 \pm 7.9^{\mathrm{dd}^{\prime}}$ & $0.61 \pm 8.1^{\mathrm{cd}^{\prime}}$ & $2.14 \pm 10.8^{\mathrm{aa}}$ & $2.42 \pm 9.9^{\mathrm{aa}^{\prime}}$ & $1.81 \pm 0.9^{\mathrm{ba}^{\prime}}$ \\
\hline \multirow{4}{*}{$\begin{array}{l}\text { AsA } \\
\text { redox }\end{array}$} & 0 & $0.887 \pm 0.09^{\mathrm{aa}^{\prime}}$ & $0.893 \pm 0.09^{\mathrm{aa}^{\prime}}$ & $0.911 \pm 0.08^{\mathrm{aa}^{\prime}}$ & $0.915 \pm 0.10^{\mathrm{aa}^{\prime}}$ & $0.905 \pm 0.1^{\mathrm{aa}^{\prime}}$ & $0.90 \pm 0.1^{\mathrm{aa}^{\prime}}$ & $0.891 \pm 0.09^{\mathrm{aa}^{\prime}}$ \\
\hline & 15 & $0.632 \pm 0.11^{\mathrm{ab}^{\prime}}$ & $0.643 \pm 0.10^{\mathrm{ab}^{\prime}}$ & $0.557 \pm 0.12^{\mathrm{bb}^{\prime}}$ & $0.619 \pm 0.09^{\mathrm{ab}^{\prime}}$ & $0.645 \pm 0.1^{\mathrm{ab}^{\prime}}$ & $0.647 \pm 0.1^{\mathrm{ac}}$ & $0.860 \pm 0.09^{\mathrm{ba}}$ \\
\hline & 30 & $0.842 \pm 0.08^{\mathrm{ba}^{\prime}}$ & $0.901 \pm 0.09^{\mathrm{aa}^{\prime}}$ & $0.468 \pm 0.09^{b c^{\prime}}$ & $0.497 \pm 0.11^{b c^{\prime}}$ & $0.970 \pm 0.11^{\text {aa }}$ & $0.891 \pm 0.1^{\mathrm{ab}^{\prime}}$ & $0.855 \pm 0.09^{\mathrm{ba}^{\prime}}$ \\
\hline & 60 & $0.861 \pm 0.09^{\mathrm{ca}^{\prime}}$ & $0.958 \pm 0.11^{\mathrm{aa}^{\prime}}$ & $0.305 \pm 0.09^{\mathrm{dd}^{\prime}}$ & $0.315 \pm 0.12^{\mathrm{dd}^{\prime}}$ & $0.930 \pm 0.11^{\mathrm{ba}^{\prime}}$ & $0.977 \pm 0.1^{\mathrm{aa}^{\prime}}$ & $0.859 \pm 0.09^{\mathrm{ca}^{\prime}}$ \\
\hline \multirow{4}{*}{ SOD } & 0 & $111.5 \pm 5.1^{\mathrm{ac}^{\prime}}$ & $118.9 \pm 4.9^{\mathrm{ac}^{\prime}}$ & $113.3 \pm 4.7^{\mathrm{ab}^{\prime}}$ & $111.5 \pm 5.5^{\mathrm{ab}^{\prime}}$ & $123.9 \pm 4.9^{\mathrm{ac}^{\prime}}$ & $118.7 \pm 4.9^{\mathrm{ac}^{\prime}}$ & $116.5 \pm 4.9^{\mathrm{ad}^{\prime}}$ \\
\hline & 15 & $130.9 \pm 5.8^{\mathrm{bb}}$ & $147.8 \pm 4.8^{\mathrm{ab}^{\prime}}$ & $46.7 \pm 5.1^{\mathrm{cc}^{\prime}}$ & $37.6 \pm 7.7^{\mathrm{dc}^{\prime}}$ & $143.9 \pm 4.8^{\mathrm{ab}}$ & $147.2 \pm 4.8^{\mathrm{ab}^{\prime}}$ & $136.5 \pm 4.9^{\mathrm{bc}}$ \\
\hline & 30 & $158.8 \pm 4.8^{\mathrm{ca}^{\prime}}$ & $191.8 \pm 10.5^{\mathrm{aa}^{\prime}}$ & $192.6 \pm 9.8^{\mathrm{aa}^{\prime}}$ & $179.8 \pm 8.5^{\mathrm{ba}^{\prime}}$ & $189.8 \pm 10.5^{\mathrm{aa}^{\prime}}$ & $194.8 \pm 10.5^{\mathrm{aa}^{\prime}}$ & $176.5 \pm 4.9^{\mathrm{bb}}$ \\
\hline & 60 & $161.6 \pm 11.6^{\mathrm{ab}^{\prime}}$ & $190.6 \pm 9.8^{\mathrm{aa}^{\prime}}$ & $195.1 \pm 6.9^{\mathrm{aa}^{\prime}}$ & $187.5 \pm 10.2^{\mathrm{aa}^{\prime}}$ & $191.89 \pm 10.5^{\mathrm{aa}^{\prime}}$ & $199.8 \pm 10.5^{\mathrm{aa}^{\prime}}$ & $200.5 \pm 4.9^{\mathrm{aa}^{\prime}}$ \\
\hline \multirow{4}{*}{ APX } & 0 & $175.8 \pm 7.8^{\mathrm{ab}^{\prime}}$ & $179.9 \pm 8.1^{\mathrm{ab}^{\prime}}$ & $179.5 \pm 8.9^{\mathrm{aa}^{\prime}}$ & $181.7 \pm 10.0^{\mathrm{aa}^{\prime}}$ & $175.9 \pm 8.1^{\mathrm{ab}^{\prime}}$ & $182.9 \pm 8.1^{\mathrm{ab}^{\prime}}$ & $181.3 \pm 8.1^{\mathrm{aa}^{\prime}}$ \\
\hline & 15 & $94.7 \pm 8.6^{\mathrm{cc}^{\prime}}$ & $87.7 \pm 12.6^{\mathrm{cc}^{\prime}}$ & $178.3 \pm 4.3^{\mathrm{ba}}$ & $183.73 \pm 4.5^{\mathrm{ba}^{\prime}}$ & $338.8 \pm 10^{\mathrm{aa}^{\prime}}$ & $375.1 \pm 10.0^{\mathrm{aa}^{\prime}}$ & $181.0 \pm 9.2^{\mathrm{ba}^{\prime}}$ \\
\hline & 30 & $350.9 \pm 4.9^{\mathrm{aa}^{\prime}}$ & $329.6 \pm 9.3^{\mathrm{aa}^{\prime}}$ & $100.4 \pm 18.5^{\mathrm{cb}^{\prime}}$ & $98.8 \pm 13.2^{\mathrm{cb}^{\prime}}$ & $97.9 \pm 11.2^{\mathrm{cd}^{\prime}}$ & $108.8 \pm 10.8^{\mathrm{cc}^{\prime}}$ & $176.3 \pm 6.6^{\mathrm{ba}^{\prime}}$ \\
\hline & 60 & $358.7 \pm 6.1^{\mathrm{aa}^{\prime}}$ & $311.3 \pm 5.5^{\mathrm{aa}^{\prime}}$ & $111.5 \pm 11.3^{\mathrm{bb}^{\prime}}$ & $107.1 \pm 10.9^{\mathrm{bb}^{\prime}}$ & $101.9 \pm 11.6^{b c^{\prime}}$ & $107.9 \pm 11.8^{\mathrm{bc}^{\prime}}$ & $161.6 \pm 7.1^{\mathrm{ab}^{\prime}}$ \\
\hline \multirow{4}{*}{ CAT } & 0 & $39.1 \pm 4.7^{\mathrm{ab}^{\prime}}$ & $40.1 \pm 6.7^{\mathrm{ab}^{\prime}}$ & $37.7 \pm 5.1^{\mathrm{aa}^{\prime}}$ & $39.8 \pm 5.6^{\mathrm{aa}^{\prime}}$ & $44.8 \pm 5.3^{\mathrm{ab}^{\prime}}$ & $49.8 \pm 5.9^{\mathrm{ab}^{\prime}}$ & $42.1 \pm 4.9^{\mathrm{aa}^{\prime}}$ \\
\hline & 15 & $60.5 \pm 3.8^{\mathrm{aa}^{\prime}}$ & $68.8 \pm 6.4^{\mathrm{aa}^{\prime}}$ & $38.6 \pm 4.9^{\mathrm{ba}^{\prime}}$ & $40.9 \pm 5.7^{\mathrm{ba}^{\prime}}$ & $20.8 \pm 5.9^{\mathrm{cc}^{\prime}}$ & $24.9 \pm 4.8^{\mathrm{ccc}^{\prime}}$ & $42.8 \pm 5.2^{\mathrm{ba}^{\prime}}$ \\
\hline & 30 & $18.5 \pm 4.1^{\mathrm{cc}^{\prime}}$ & $20.3 \pm 4.7^{\mathrm{cc}^{\prime}}$ & $11.7 \pm 3.5$ & $13.3 \pm 6.0^{\mathrm{cb}^{\prime}}$ & $133.3 \pm 7.9^{\mathrm{aa}^{\prime}}$ & $151.3 \pm 8.8^{\mathrm{aa}^{\prime}}$ & $49.1 \pm 4.9^{\mathrm{ba}^{\prime}}$ \\
\hline & 60 & $16.7 \pm 5.0^{c c^{\prime}}$ & $18.9 \pm 5.1^{\mathrm{cc}^{\prime}}$ & $8.6 \pm 6.1^{\mathrm{db}^{\prime}}$ & $10.7 \pm 5.9^{\mathrm{db}^{\prime}}$ & $137.5 \pm 8.9^{\mathrm{aa}^{\prime}}$ & $163.5 \pm 10.9^{\mathrm{aa}^{\prime}}$ & $50.1 \pm 4.9^{\mathrm{ba}^{\prime}}$ \\
\hline
\end{tabular}

Data were presented as means \pm SE of four replicates. Different small letters in each row indicate significant differences among genotypes and letters with prime in each column indicate significant differences among treatments (for a particular trait) at $P \leq 0.05$ by ANOVA followed by Duncan's multiple range test. Controls of each genotype exhibited nonsignificant $(P>0.05)$ differences and thus mean of all controls is presented here.

57] and Phaseolus aureus [60]. Present result is in partial agreement with these results. Increase in proline level was observed in B1, BioL-212, LR3, and LR4 from 30 DAC and it was maintained till 60 DAC. However, it is noteworthy that seedlings from all genotypes faced severe growth inhibition at 15 DAC even when proline level was close to control value. Significantly enough, proline level was control like in both PUSA-90-2 and WBK-CB-14 throughout the growth period although the genotypes continuously suffered growth inhibition. Proline accumulation in plants was regarded as a symptom of stress in less-salinity-tolerant species, and its contribution to osmotic adjustment was found negligible as compared with $\mathrm{K}^{+}[2]$. Certainly, this is not the situation in the present case. Higher accumulation of proline in four genotypes showing good biomass accumulation at $30 \mathrm{DAC}$ and at 60 DAC suggested its responsiveness during reproductive development of plant conferring protection against salt-induced osmotic disruption in tolerant genotypes. Its usual level during salt-induced growth inhibition, however, requires further study.

Equilibrium of cellular $\mathrm{Na}^{+}$and $\mathrm{K}^{+}$content is absolutely essential in imparting salinity tolerance in plants [36, 41]. Excessive accumulation of $\mathrm{Na}^{+}$in leaves has been considered highly harmful for normal metabolism of plant, and tolerant genotype has the capacity of successful salt exclusion $[13,36]$. Salt stress also impairs $\mathrm{K}^{+}$uptake of plants, and it has been suggested that $\mathrm{K}^{+}$deficiency might be a contributing factor to salt-induced growth inhibition through induction of oxidative stress and related cell damage $[57,61,62]$. The $\mathrm{K}^{+}: \mathrm{Na}^{+}$ ratio has been used as a discriminating factor between tolerant and sensitive genotypes with greater capacity of former to block or reduce the uptake or exclude the excess amount of $\mathrm{Na}^{+}$and associated increase in $\mathrm{K}^{+}$content [36]. In the present material, reduction in $\mathrm{K}$ uptake and transport to aerial part of plants under salinity in competition with higher $\mathrm{Na}$ absorption resulted in decrease in $\mathrm{K}^{+}: \mathrm{Na}^{+}$ratio and low plant biomass production in all the six genotypes at 15 DAC, and in PUSA-90-2 and WBK-CB-14 at 30 DAC and also, at 60 DAC. Growing evidences indicate that abnormal accumulation of $\mathrm{Na}^{+}$and/or $\mathrm{K}^{+}$deficiency severely disrupts photosynthetic capability and impeded translocation of photosynthates from leaves into sink organs [36, 57, 63], and might be one of the prime reasons for reduction in photosynthetic capacity during salt-sensitivity of the present genotypes. In salt-sensitive Phaseolus species, $\mathrm{K}^{+}$deficiency combined with salt stress induced a reduction in $\mathrm{CO}_{2}$ photo assimilation and stomata closure [62]. Similar situation was encountered in salt-sensitive genotypes and mutant lines of 
grass pea experiencing different $\mathrm{NaCl}$-treatment regimes [39, $41,55]$. By contrast, higher level of $\mathrm{K}^{+}$content than $\mathrm{Na}^{+}$ pushed $\mathrm{K}^{+}: \mathrm{Na}^{+}$ratio to quite normal level and ensured better plant growth in B1, BioL-212, LR3, and LR4 genotypes at later stages of growth despite prolonged $\mathrm{NaCl}$-treatment. The result indicated that early surge in $\mathrm{Na}^{+}$accumulation and low $\mathrm{K}^{+}: \mathrm{Na}^{+}$ratio may be detrimental to vegetative growth but its normal (control like) level is crucial in reproductive stages to maintain flowering and subsequent grain-filling stage under salt-exposure. Normal (control like) concentration of $\mathrm{K}^{+}$and $\mathrm{K}^{+}: \mathrm{Na}^{+}$ratio at $30 \mathrm{DAC}$ and also at $60 \mathrm{DAC}$ in these four genotypes might be orchestrated through a compensation over time, presumably through translocation of $\mathrm{K}^{+}$from roots and stems to leaves [61], a sustained acquisition despite appreciable overall $\mathrm{Na}^{+}$uptake $[1,62]$, a high $\mathrm{K}^{+}$selectivity and/or $\mathrm{K}^{+} / \mathrm{Na}^{+}$exchange across the plasmalemma of the root epidermis $[34,39,57]$. The maintenance of higher leaf $\mathrm{K}^{+}$concentrations and $\mathrm{K}^{+}: \mathrm{Na}^{+}$ratio in the present grass pea genotypes showing good growth under salinity strongly indicated their ability to withdraw $\mathrm{Na}^{+}$and to retranslocate $\mathrm{K}^{+}$during reproductive stages which seems to be highly crucial for superior salt tolerance [61], as explained in saltstressed grass pea [39], beans [62] and barley seedlings [61].

Perhaps, one of the most intriguing questions in the present investigation is the remarkable capacity of four grass pea genotypes to restore their normal growth at flowering stage (30 DAC) and its maintenance through early podbearing stages $(60 \mathrm{DAC})$ despite them experiencing prolonged salt exposure. In order to ascertain this apparent conflicting situation, response of four primary defense components involved in $\mathrm{H}_{2} \mathrm{O}_{2}$-metabolism and concomitant oxidative stress response were studied. These four components play vital roles in primary defense mechanism of plants during ROS-detoxification [11]. $\mathrm{H}_{2} \mathrm{O}_{2}$ is a highly diffusible ROS across cellular membranes and inflicts oxidative damage to thiol-containing enzymes $[6-8,11,64]$. On the other hand, it can induce antioxidant defense to be upregulated against oxidative stress as a signaling molecule $[6,7,10]$. Therefore, regulation of its concentration at a particular level within cellular environment is the most vital during plant growth and development $[8,10,64]$. In the present study, a timebound measurements at 15,30 and $60 \mathrm{DAC}$ revealed huge increase of $\mathrm{H}_{2} \mathrm{O}_{2}$ level in leaves of $\mathrm{B} 1, \mathrm{BioL}-212, \mathrm{LR} 3$, and LR4 but a significant decline in PUSA-90-2 and WBK-CB-14 at 15 DAC, followed by a remarkable rise in PUSA-90-2 and WBK-CB-14 and decrease in the rest of the four genotypes at $30 \mathrm{DAC}$ and $60 \mathrm{DAC}$. Interestingly enough, the level of $\mathrm{H}_{2} \mathrm{O}_{2}$ in B1, BioL-212, LR3, and LR4 at 30 DAC was still higher than that in control and this level was maintained at 60 DAC. This situation can be better explained if enzymatic regulation of $\mathrm{H}_{2} \mathrm{O}_{2}$-metabolism is taken into account. High $\mathrm{SOD}$ activity strongly suggested $\mathrm{NaCl}$-induced generation of excess superoxide radicals and thus, formed huge $\mathrm{H}_{2} \mathrm{O}_{2}$ in B1, BioL-212, LR3, and LR4 genotypes at 15 DAC, and in the rest of the genotypes up to 60 DAC. In many studies, up-regulation of SOD, APX and CAT activities was cited as prime reason for salt-tolerance while their decreased level was associated with onset of salt-induced oxidative stress in sensitive genotypes [39, 57, 65]. However, the intrinsic relationship among these three prominent $\mathrm{H}_{2} \mathrm{O}_{2}$ metabolizing enzymes is not straightforward in the present case. Both APX and CAT activities were quite normal in PUSA-90-2 and WBK-CB-14 genotypes at 15 DAC but it reduced significantly at $30 \mathrm{DAC}$ and $60 \mathrm{DAC}$. Completely reverse response, however, was noticed between activity of APX and CAT in the rest of the four genotypes throughout the treatment period. Declining APX level in B1 and BioL212 was accompanied by high CAT activity at 15 DAC which went just reverse during later stages of growth. Similarly, high APX activity in the two mutant lines was associated with abrupt fall in CAT level at 15 DAC, followed by decline in APX activity and concomitant increase in CAT level at 30 DAC and 60 DAC. The results clearly indicated that low SOD activity coupled with normal level of both APX and CAT might be responsible for significant fall in $\mathrm{H}_{2} \mathrm{O}_{2}$ generation in PUSA90-2 and WBK-CB-14 during early stages of treatment. At the same period, low APX level accompanied with high SOD activity might have attributed to over-accumulation of $\mathrm{H}_{2} \mathrm{O}_{2}$ in $\mathrm{B} 1$ and BioL-212, indicating failure of $\mathrm{H}_{2} \mathrm{O}_{2}$-scavenging machinery within AsA-GSH cycle, and CAT alone could not cope up with rising level of $\mathrm{H}_{2} \mathrm{O}_{2}$ at early growth stages. By contrast, rise in $\mathrm{H}_{2} \mathrm{O}_{2}$ level in LR3 and LR4 mutant lines was presumably due to abnormal fall in CAT activity and despite high APX level, $\mathrm{H}_{2} \mathrm{O}_{2}$ was generated in excess amount due to high SOD activity. This situation got remarkable twist once the treated plants entered flowering and subsequent pod-bearing stage. High APX activity coupled with low CAT level in B1 and BioL-212 and low APX combined with high CAT activity in LR3 and LR4 mutant lines in the backdrop of enhanced SOD activity led to decrease in $\mathrm{H}_{2} \mathrm{O}_{2}$ level in a particular concentration. This level was still higher than control but was not toxic to plant growth and development at reproductive period under $\mathrm{NaCl}$-exposure. Presumably, leaf $\mathrm{H}_{2} \mathrm{O}_{2}$ concentration in these four genotypes was regulated in controlled way by opposite mechanisms of prominent $\mathrm{H}_{2} \mathrm{O}_{2}$-metabolizing enzymes, balancing it to a particular level during later stages of growth. This critical balance, however, was lost when APX activity coupled with CAT began to decline and SOD activity was enhanced in PUSA-90-2 and WBK-CB-14 during $30 \mathrm{DAC}$ and $60 \mathrm{DAC}$, resulting in unregulated generation and accumulation of $\mathrm{H}_{2} \mathrm{O}_{2}$ in treated genotypes. Obviously, a well-integrated catalase-peroxidase system along with SOD was instrumental in regulation of $\mathrm{H}_{2} \mathrm{O}_{2}$-metabolism in stressed plants in different manners, and this is distinctly functional at reproductive stages of growth. Declining level of APX might be due to significant reduction in AsA level and its redox state. Besides serving as cofactor of APX, AsA itself can detoxify ROS through nonenzymatic mechanism $[64,66]$ and its availability and redox state plays key roles in signaling network through controlled metabolism of $\mathrm{H}_{2} \mathrm{O}_{2}$ during NaCl-stress [66]. Prolonged $\mathrm{NaCl}$-exposure, presumably, led to crippling of AsAmediated antioxidant defense in PUSA-90-2 and WBK-CB14 , resulting in significant rise of $\mathrm{H}_{2} \mathrm{O}_{2}$ content under $\mathrm{NaCl}-$ treatment. The decline in CAT activity at 30 and 60 DAC further aggravated the situation. $\mathrm{H}_{2} \mathrm{O}_{2}$ has a longer half-life than superoxides [7], and therefore its initial surge in leaves of four tolerant genotypes indicated early "oxidative burst" 
in the photosynthetic organs which might trigger enhanced defense response against excess ROS at later stages of growth. Rise in either APX activity powered by high AsA content or AsA-redox and increasing CAT level at $30 \mathrm{DAC}$ and 60 DAC in B1, BioL-212, LR3, and LR4 was the strong enough to stimulate antioxidant response, and might be instrumental to maintain $\mathrm{H}_{2} \mathrm{O}_{2}$ at a particular level. Presumably, $\mathrm{H}_{2} \mathrm{O}_{2}$ played dual roles in stress perception of $\mathrm{NaCl}$-treated grass pea genotypes plants in a concentration-dependent manner; it promoted plant growth in B1, BioL-212, LR3, and LR4 at $30 \mathrm{DAC}$ and $60 \mathrm{DAC}$ in a concentration higher than control but induced toxicity in these four genotypes at the far higher level during 15 DAC. Certainly, the status of cellular $\mathrm{H}_{2} \mathrm{O}_{2}$ informed the plant cell about the severity of the oxidative stress and hence the appropriate level of antioxidant enzyme activities through induction $[6,8,10]$. Present results indicates that the $\mathrm{H}_{2} \mathrm{O}_{2}$ level is highly critical in stress perception, which can be regulated/adjusted in favor of plant growth and yield performances during prolonged exposure to high $\mathrm{NaCl}$.

Obviously, extremely low $\mathrm{H}_{2} \mathrm{O}_{2}$ level in PUSA-90-2 and WBK-CB-14 at 15 DAC was not enough to upregulate antioxidant defense against $\mathrm{NaCl}$-induced oxidative stress. On the other hand, its huge surge was associated with significant accumulation of MDA content in B1, BioL-212, LR3, and LR4 at 15 DAC and in PUSA-90-2 and WBK-CB-14 at 30 DAC and 60 DAC. MDA along with high $\mathrm{H}_{2} \mathrm{O}_{2}$ level was commonly used as cellular markers of salinity-induced oxidative stress in sensitive genotypes $[5,37,39,57,59]$. However, the relationship between $\mathrm{H}_{2} \mathrm{O}_{2}$ content and oxidative stress is not straightforward in the present case. The absence of oxidative stress symptom in shoots of B1, BioL-212, LR3, and LR4 lines at 60 DAC despite the high $\mathrm{H}_{2} \mathrm{O}_{2}$ content might be due to the significantly low level of membrane lipid peroxidation and electrolyte leakage. Similarly, low $\mathrm{H}_{2} \mathrm{O}_{2}$ level in PUSA90-2 and WBK-CB-14 at 15 DAC did not guarantee low oxidative damage, as MDA as well as EL\% was quite high in these two genotypes at this stage. Rising MDA content and EL\% in treated genotypes might be instrumental in lowering of photosynthesis by damaging the photosynthetic pigment composition and stability along with low $\mathrm{K}^{+}$content is probably responsible for lower pigment levels in $\mathrm{NaCl}$-treated B1, BioL-212, LR3, and LR4 at 15 DAC and in PUSA-90-2 and WBK-CB-14 varieties throughout the treatment period. Similar situation was also observed in salt-affected cereals, legumes and other vegetable crops $[34,39,57,61,67]$. Significant increase in MDA content and loss in photosynthetic apparatus have been recognized as the marks of oxidative stress in plants $[5,6,10,39,57,64,68,69]$ and may be one of the prime reasons for $\mathrm{NaCl}$-induced growth inhibition in the present material. It is also clear that oxidative damage at initial growth stages was effectively prevented in four genotypes by mitigating membrane damage at reproductive stage, but it was quite impossible for the PUSA-90-2 and WBK-CB14 varieties to recover from $\mathrm{NaCl}$-induced oxidative damage due to complete failure of antioxidant defense throughout the treatment period.
Changes in antioxidant enzyme activities coincided with a variable increase or decrease of their individual isoformexpression. Analysis of isoforms and inhibitor studies revealed that the increase in SOD activity in B1, BioL-212, LR3, and LR4 lines over control was purely due to over-activity of both $\mathrm{Cu} / \mathrm{Zn} \mathrm{I}$ and II isoforms, as suggested by high staining intensity. On the other hand, significant enhancement in SOD activity at 30 DAC was mainly due to origin of a new Mn SOD I isoform in LR3, one Fe SOD isoform in LR4 line and two new Mn SOD isoforms (I and II), in addition to existing $\mathrm{Cu} / \mathrm{Zn}$ isoforms. No new isoforms were observed at 60 DAC. Thus, further increase in activity of SOD might be attributed to enhanced expression of existing isoforms, visualized as stronger intensity. The supply of $\mathrm{NaCl}$ reportedly enhanced the activity of $\mathrm{Cu} / \mathrm{Zn}$-SOD II in wheat seedlings [70]. The present result revealed origin of three novel isoforms namely two Mn SODs (I and II) and one $\mathrm{Fe}$ SOD at $30 \mathrm{DAC}$ and it was observed at $60 \mathrm{DAC}$, also. It seems likely that increased activity of SOD at 15 DAC was mainly mediated through existing isoforms but as the treatment progressed induction of SOD expression was required in different cellular compartments to combat the elevated generation of superoxide radicals due to prolonged $\mathrm{NaCl}$-exposure. While $\mathrm{Cu} / \mathrm{Zn}$ isoforms are predominantly present in chloroplast and cytosol, Mn SODs are located in peroxisomes and mitochondria and Fe SODs are mainly chloroplastidic [9], suggesting participation of SOD isoforms in different cellular compartments to combat $\mathrm{NaCl}$-induced generation of free radicals in the present material. For APX, the increased activity was mainly due to enhanced expression of APX 1, APX 2 and APX 3 isozymes, as was evidenced by strongly intense bands in zymograms. On the other hand, the decreased activity of APX was manifested by diminishing intensity of different APX bands. Leaf APX isoforms are rapidly deactivated by over-accumulating $\mathrm{H}_{2} \mathrm{O}_{2}$ at low AsA pool [71], and this was, perhaps, one of the prime reasons for reduced APX level in treated genotypes at different growth stages. CAT activity was uniformly visualized as a single zone across the treatments. However, the increasing staining intensity confirmed the enhanced level of CAT expression in treated genotypes. Induction of new SOD isoforms at $30 \mathrm{DAC}$ and their retaining till $60 \mathrm{DAC}$, however, is interesting and has immense significance as the plants were then at flowering and pod-bearing stages and major changes (increase or decrease) in $\mathrm{H}_{2} \mathrm{O}_{2}$ level occurred in this period. Present results clearly indicated criticality of blooming stage in determining regulation of $\mathrm{H}_{2} \mathrm{O}_{2}$-metabolism through $\mathrm{NaCl}$-induced enzyme expression. The variations in the isozyme pattern and their correspondence to total assayed activity suggested that the three $\mathrm{H}_{2} \mathrm{O}_{2}$-metabolizing enzymes responded strongly to $\mathrm{NaCl}$-induced oxidative stress in grass pea genotypes.

\section{Conclusions}

For the first time, effect of prolonged NaCl-treatment was studied in six promising grass pea genotypes. Results revealed significant genotypic differences in response to 
$150 \mathrm{mM} \mathrm{NaCl}$-treatment and even differences between growth stages of a particular genotype. NaCl-treatment significantly reduced dry matter production in all six genotypes at early vegetative stage by inhibiting photosynthetic capacity probably orchestrated through diminishing level of $\mathrm{K}^{+}$, low $\mathrm{K}^{+} / \mathrm{Na}^{+}$ratio and onset of severe oxidative stress. The negative impact of $\mathrm{NaCl}$-stress was ameliorated in B1, BioL-212, LR3, and LR4 at later stages of growth through modulation of $\mathrm{H}_{2} \mathrm{O}_{2}$-metabolism in fine tune by balanced action of SOD, APX and CAT. This along with healthy ionic balance in favor of $\mathrm{K}^{+}$helped these four genotypes to maintain normal growth through restoration of normal photosynthetic capacity. This balance, however, was completely lost in PUSA-90-2 and WBK-CB-14 genotypes at the most crucial stages of reproductive growth, leading to un-regulated accumulation of $\mathrm{H}_{2} \mathrm{O}_{2}$ and high rate of lipid peroxidation as the marks of oxidative stress. Present result also suggested differential response of CAT/APX system during scavenging of $\mathrm{H}_{2} \mathrm{O}_{2}$ in four tolerant genotypes. Isozyme analysis revealed origin of unique isoforms of SOD in response to As treatment and increase in activity of existing isoforms of SOD, APX, and CAT, conferring enhanced activity of the enzymes. Considering the overall response of growth and leaf antioxidant metabolism of six grass pea genotypes, it can be finally concluded that var. B1 and BioL-212 along with LR3 and LR 4 mutant lines are tolerant to NaCl-stress while var. PUSA-90-2 and WBKCB-14 are highly salt sensitive. $\mathrm{H}_{2} \mathrm{O}_{2}$-metabolism holds the key in determining sensitivity of grass pea genotypes to prolonged exposure of $\mathrm{NaCl}$-induced oxidative stress. Understanding the intrinsic modulation of physiological and antioxidant metabolism by $\mathrm{H}_{2} \mathrm{O}_{2}$ through different growth stages would be an important step in formulating effective breeding strategies for improving $\mathrm{NaCl}$-tolerance in crop plants.

\section{Conflict of Interests}

The author declares that there is no conflict of interests regarding the publication of this paper.

\section{Acknowledgments}

The author is thankful to University Grants Commission, ERO, Calcutta, India, for granting financial assistance in the form of research project (Grant no. PSW-047/11-12 ERO) to carry out present work. Technical assistance from Dr. Tulika Talukdar and guidance from Dr. Zahed Hossain during the experimentation are gratefully acknowledged. Thanks are also due to Dr. Madan Srivastava, Joint Director Pulses (in Pulses and Oilseeds Research Station, Berhampur, West Bengal) for kindly providing the verified seed samples.

\section{References}

[1] J. S. Bayuelo-Jiménez, D. G. Debouck, and J. P. Lynch, "Salinity tolerance in Phaseolus species during early vegetative growth," Crop Science, vol. 42, no. 6, pp. 2184-2192, 2002.
[2] W. Wang, B. Vinocur, and A. Altman, "Plant responses to drought, salinity and extreme temperatures: towards genetic engineering for stress tolerance," Planta, vol. 218, no. 1, pp. 1-14, 2003.

[3] P. H. Graham and C. P. Vance, "Legumes: importance and constraints to greater use," Plant Physiology, vol. 131, no. 3, pp. 872-877, 2003.

[4] Z. Hossain, A. K. A. Mandal, R. Shukla, and S. K. Datta, "NaCl stress: its chromotoxic effects and antioxidant behavior in roots of Chrysanthemum morifolium Ramat," Plant Science, vol. 166, no. 1, pp. 215-220, 2004.

[5] J. A. Hernández, A. Jiménez, P. Mullineaux, and F. Sevilla, "Tolerance of pea (Pisum sativum L.) to long-term salt stress is associated with induction of antioxidant defences," Plant, Cell and Environment, vol. 23, no. 8, pp. 853-862, 2000.

[6] D. Talukdar, "Exogenous calcium alleviates the impact of cadmium-induced oxidative stress in Lens culinaris Medic. seedlings through modulation of antioxidant enzyme activities," Journal of Crop Science and Biotechnology, vol. 15, no. 4, pp. 325334, 2012.

[7] S. Neill, R. Desikan, and J. Hancock, "Hydrogen peroxide signalling," Current Opinion in Plant Biology, vol. 5, no. 5, pp. 388-395, 2002.

[8] X. Hu, M. Jiang, J. Zhang, A. Zhang, F. Lin, and M. Tan, "Calcium-calmodulin is required for abscisic acid-induced antioxidant defense and functions both upstream and downstream of $\mathrm{H}_{2} \mathrm{O}_{2}$ production in leaves of maize ( $\mathrm{Cea}$ mays) plants," New Phytologist, vol. 173, no. 1, pp. 27-38, 2007.

[9] R. G. Alscher, N. Erturk, and L. S. Heath, "Role of superoxide dismutases (SODs) in controlling oxidative stress in plants," Journal of Experimental Botany, vol. 53, no. 372, pp. 1331-1341, 2002.

[10] D. Talukdar, "Arsenic-induced changes in growth and antioxidant metabolism of fenugreek," Russian Journal of Plant Physiology, vol. 60, no. 5, pp. 652-660, 2013.

[11] C. H. Foyer and G. Noctor, "Redox sensing and signalling associated with reactive oxygen in chloroplasts, peroxisomes and mitochondria," Physiologia Plantarum, vol. 119, no. 3, pp. 355-364, 2003.

[12] N. Anoop and A. K. Gupta, "Transgenic indica rice cv IR-50 over-expressing Vigna aconitifolia $\Delta$ 1-Pyrroline-5-carboxylate synthetase cDNA shows tolerance to high salt," Journal of Plant Biochemistry and Biotechnology, vol. 12, no. 2, pp. 109-116, 2003.

[13] T. J. Flowers, "Improving crop salt tolerance," Journal of Experimental Botany, vol. 55, no. 396, pp. 307-319, 2004.

[14] C. Chen, C. Tao, H. Peng, and Y. Ding, "Genetic analysis of salt stress responses in asparagus bean (Vigna unguiculata (L.) ssp. sesquipedalis Verdc.)," Journal of Heredity, vol. 98, no. 7, pp. 655-665, 2007.

[15] D. Talukdar, "Dwarf mutations in grass pea (Lathyrus sativus L.): origin, morphology, inheritance and linkage studies," Journal of Genetics, vol. 88, no. 2, pp. 165-175, 2009.

[16] M. T. Jackson and A. G. Yunus, "Variation in the grass pea (Lathyrus sativus L.) and wild species," Euphytica, vol. 33, no. 2, pp. 549-559, 1984.

[17] D. Talukdar, "Recent progress on genetic analysis of novel mutants and aneuploid research in grass pea (Lathyrus sativus L.)," African Journal of Agricultural Research, vol. 4, no. 13, pp. 1549-1559, 2009. 
[18] E. Pastor-Cavada, R. Juan, J. E. Pastor, M. Alaiz, and J. Vioque, "Antioxidant activity of seed polyphenols in fifteen wild Lathyrus species from South Spain," Food Science and Technology, vol. 42, no. 3, pp. 705-709, 2009.

[19] D. Talukdar, "Antioxidant potential and type II diabetes related enzyme inhibition properties of raw and processed legumes in Indian Himalayas," Journal of Applied Pharmaceutical Science, vol. 3, no. 3, pp. 013-019, 2013.

[20] D. Talukdar, "In Vitro antioxidant potential and type II diabetes related enzyme inhibition properties of traditionally processed legume-based food and medicinal recipes in Indian Himalayas," Journal of Applied Pharmaceutical Science, vol. 3, no. 1, pp. 026032, 2013.

[21] D. Talukdar, "Cytogenetic characterization of seven different primary tetrasomics in grass pea (Lathyrus sativus L.)," Caryologia, vol. 61, no. 4, pp. 402-410, 2008.

[22] S. Kumar, G. Bejiga, S. Ahmed, H. Nakkoul, and A. Sarker, "Genetic improvement of grass pea for low neurotoxin $(\beta$ ODAP) content," Food and Chemical Toxicology, vol. 49, no. 3, pp. 589-600, 2011.

[23] D. Talukdar and A. K. Biswas, "Induced seed coat colour mutations and their inheritance in grass pea (Lathyrus sativusL.)," Indian Journal of Genetics and Plant Breeding, vol. 65, no. 2, pp. 135-136, 2005.

[24] D. Talukdar and A. K. Biswas, "Seven different primary trisomics in grass pea (Lathyrus sativus L.). I. Cytogenetic characterisation," Cytologia, vol. 72, no. 4, pp. 385-396, 2007.

[25] D. Talukdar, "Cytogenetics of a reciprocal translocation integrating distichous pedicel and tendril-less leaf mutations in Lathyrus sativus L.," Caryologia, vol. 66, no. 1, pp. 21-30, 2013.

[26] D. Talukdar, "Reciprocal translocations in grass pea (Lathyrus sativus 1.): pattern of transmission, detection of multiple interchanges and their independence," Journal of Heredity, vol. 101, no. 2, pp. 169-176, 2010.

[27] D. Talukdar, "Genetics of pod indehiscence in grass pea (Lathyrus sativus L.)," Journal of Crop Improvement, vol. 25, no. 2, pp. 161-175, 2011.

[28] D. Talukdar, "Cytogenetic analysis of a novel yellow flower mutant carrying a reciprocal translocation in grass pea (Lathyrus sativus L.)," Journal of Biological Research, vol. 15, pp. 123134, 2011.

[29] D. Talukdar, "Flavonoid-deficient mutants in grass pea (Lathyrus sativus L.): genetic control, linkage relationships, and mapping with aconitase and S nitrosoglutathione reductase isozyme loci," Scientific World Journal, Article ID 345983, 11 pages, 2012.

[30] M. C. Vaz Patto, B. Skiba, E. C. K. Pang, S. J. Ochatt, F. Lambein, and D. Rubiales, "Lathyrus improvement for resistance against biotic and abiotic stresses: from classical breeding to marker assisted selection," Euphytica, vol. 147, no. 1-2, pp. 133-147, 2006.

[31] D. Talukdar, "Effect of arsenic-induced toxicity on morphological traits of Trigonella foenum-graecum L. and Lathyrus sativus L. during germination and early seedling growth," Current Research Journal of Biological Sciences, vol. 3, no. 2, pp. 116-123, 2011.

[32] D. Talukdar, "A glutathione-overproducing mutant in grass pea (Lathyrus sativus L.): alterations in glutathione content, modifications in antioxidant defense response to cadmium stress and genetic analysis using primary trisomics," International Journal of Recent Scientific Research, vol. 3, no. 4, pp. 234-243, 2012.
[33] D. Talukdar, "Selenium priming selectively ameliorates weedinduced phytotoxicity by modulating antioxidant defense components in lentil (Lens culinaris Medik.) and grass pea (Lathyrus sativus L.)," Annual Review and Research in Biology, vol. 3, no. 3, pp. 195-212, 2013.

[34] D. Talukdar, "Modulation of plant growth and leaf biochemical parameters in grass pea (Lathyrus sativus L) and fenugreek (Trigonella foenum-graecum L.) exposed to $\mathrm{NaCl}$ treatments," Indian Journal of Fundamental and Applied Life Sciences, vol. 2, no. 3, pp. 20-28, 2012.

[35] B. Mahdavi and S. A. M. M. Sanavy, "Germination and seedling growth in grasspea (Lathyrus sativus) cultivars under salinity conditions," Pakistan Journal of Biological Sciences, vol. 10, no. 2, pp. 273-279, 2007.

[36] R. Munns, "Genes and salt tolerance: bringing them together," New Phytologist, vol. 167, no. 3, pp. 645-663, 2005.

[37] P. Ahmad, R. John, M. Sarwat, and S. Umar, "Responses of proline, lipid peroxidation and antioxidative enzymes in two varieties of Pisum sativum L. under salt stress," International Journal of Plant Production, vol. 2, no. 4, pp. 353-366, 2008.

[38] I. M. Santha and S. L. Mehta, "Development of low ODAP somaclones of Lathyrus sativus," Lathyrus Lathyrism Newsletter, vol. 2, article 42, 2001.

[39] D. Talukdar, "Isolation and characterization of NaCl-tolerant mutations in two important legumes, Clitoria ternatea L. and Lathyrus sativus L.: induced mutagenesis and selection by salt stress," Journal of Medicinal Plant Research, vol. 5, no. 16, pp. 3619-3628, 2011.

[40] ISTA, International Rules for Seed Testing, International Seed Testing Association, 2008.

[41] D. Talukdar, "Morpho-physiological responses of grass pea (Lathyrus sativus L.) genotypes to salt stress at germination and seedling stages," Legume Research, vol. 34, no. 4, pp. 232-241, 2011.

[42] H. K. Lichtenthaler, "Chlorophylls and carotenoids: pigments of photosynthetic biomembranes," Methods in Enzymology, vol. 148, pp. 350-382, 1987.

[43] J. Coombs, D. O. Hall, S. P. Long, and J. M. O. Scurlock, Techniques in Bioproductivity and Photosynthesis, Pergamon Press, Oxford, UK, 1985.

[44] V. Kumar and D. R. Sharma, "Isolation and characterization of sodium chloride-resistant callus culture of Vigna radiata (L.) wilczek var. radiata," Journal of Experimental Botany, vol. 40, no. 1, pp. 143-147, 1989.

[45] L. S. Bates, R. P. Waldren, and I. D. Teare, "Rapid determination of free proline for water-stress studies," Plant and Soil, vol. 39, no. 1, pp. 205-207, 1973.

[46] C.-Q. Wang, M. Chen, and B.-S. Wang, "Betacyanin accumulation in the leaves of $\mathrm{C}_{3}$ halophyte Suaeda salsa L. is induced by watering roots with $\mathrm{H}_{2} \mathrm{O}_{2}$," Plant Science, vol. 172, no. 1, pp. 1-7, 2007.

[47] D. M. Hodges, J. M. DeLong, C. F. Forney, and R. K. Prange, "Improving the thiobarbituric acid-reactive-substances assay for estimating lipid peroxidation in plant tissues containing anthocyanin and other interfering compounds," Planta, vol. 207, no. 4, pp. 604-611, 1999.

[48] M. Y. Law, S. A. Charles, and B. Halliwell, "Glutathione and ascorbic acid in spinach (Spinacia oleracea) chloroplasts. The effect of hydrogen peroxide and of Paraquat," Biochemical Journal, vol. 210, no. 3, pp. 899-903, 1983. 
[49] M. M. Bradford, "A rapid and sensitive method for the quantitation of microgram quantities of protein utilizing the principle of protein dye binding," Analytical Biochemistry, vol. 72, no. 1-2, pp. 248-254, 1976.

[50] W. F. Beyer Jr. and I. Fridovich, "Assaying for superoxide dismutase activity: some large consequences of minor changes in conditions," Analytical Biochemistry, vol. 161, no. 2, pp. 559$566,1987$.

[51] Y. Nakano and K. Asada, "Hydrogen peroxide is scavenged by ascorbate-specific peroxidase in spinach chloroplasts," Plant and Cell Physiology, vol. 22, no. 5, pp. 867-880, 1981.

[52] R. Mittler and B. A. Zilinskas, "Detection of ascorbate peroxidase activity in native gels by inhibition of the ascorbatedependent reduction of nitroblue tetrazolium," Analytical Biochemistry, vol. 212, no. 2, pp. 540-546, 1993.

[53] B. Chance and A. C. Maehly, "Assay of catalases and peroxidases," Methods in Enzymology, vol. 2, pp. 764-817, 1955.

[54] W. Woodbury, A. K. Spencer, and M. A. Stahmann, "An improved procedure using ferricyanide for detecting catalase isozymes," Analytical Biochemistry, vol. 44, no. 1, pp. 301-305, 1971.

[55] D. Talukdar, "Flower and pod production, abortion, leaf injury, yield and seed neurotoxin levels in stable dwarf mutant lines of grass pea (Lathyrus sativus L.) differing in salt stress responses," International Journal of Current Research, vol. 2, no. 1, pp. 46-54, 2011.

[56] M. A. Turan, V. Katkat, and S. Taban, "Variations in proline, chlorophyll and mineral elements contents of wheat plants grown under salinity stress," Journal of Agronomy, vol. 6, no. 1, pp. 137-141, 2007.

[57] M. A. Shahid, R. M. Balal, M. A. Pervez et al., "Differential response of pea (Pisum sativumL.) genotypes to salt stress in relation to the growth, physiological attributes antioxidant activity and organic solutes," Australian Journal of Crop Science, vol. 6, no. 5, pp. 828-838, 2012.

[58] D. A. Meloni, M. A. Oliva, C. A. Martinez, and J. Cambraia, "Photosynthesis and activity of superoxide dismutase, peroxidase and glutathione reductase in cotton under salt stress," Environmental and Experimental Botany, vol. 49, no. 1, pp. 6976, 2003.

[59] P. Saha, P. Chatterjee, and A. K. Biswas, " $\mathrm{NaCl}$ pretreatment alleviates salt stress by enhancement of antioxidant defense system and osmolyte accumulation in mungbean (Vigna radiata 1. wilczek)," Indian Journal of Experimental Biology, vol. 48, no. 6, pp. 593-600, 2010.

[60] N. Misra and A. K. Gupta, "Effect of salt stress on proline metabolism in two high yielding genotypes of green gram," Plant Science, vol.169, no. 2, pp. 331-339, 2005.

[61] E. Degl'Innocenti, C. Hafsi, L. Guidi, and F. Navari-Izzo, "The effect of salinity on photosynthetic activity in potassiumdeficient barley species," Journal of Plant Physiology, vol. 166, no. 18, pp. 1968-1981, 2009.

[62] J. S. Bayuelo-Jimenez, N. Jasso-Plata, and I. Ochoa, "Growth and physiological responses of Phaseolus species to salinity stress," International Journal of Agronomy, vol. 2012, Article ID 527673, 13 pages, 2012.

[63] V. Arbona, A. J. Marco, D. J. Iglesias, M. F. López-Climent, M. Talon, and A. Gómez-Cadenas, "Carbohydrate depletion in roots and leaves of salt-stressed potted Citrus clementina L," Plant Growth Regulation, vol. 46, no. 2, pp. 153-160, 2005.
[64] D. Talukdar, "Ascorbate deficient semi-dwarf asfL1 mutant of Lathyrus sativus exhibits alterations in antioxidant defense," Biologia Plantarum, vol. 54, no. 4, pp. 675-682, 2012.

[65] Z. Noreen and M. Ashraf, "Assessment of variation in antioxidative defense system in salt-treated pea (Pisum sativum) cultivars and its putative use as salinity tolerance markers," Journal of Plant Physiology, vol. 166, no. 16, pp. 1764-1774, 2009.

[66] N. Smirnoff, "Ascorbic acid: metabolism and functions of a multi-facetted molecule," Current Opinion in Plant Biology, vol. 3, no. 3, pp. 229-235, 2000.

[67] C. Pandolfi, S. Mancuso, and S. Shabala, "Physiology of acclimation to salinity stress in pea (Pisum sativum)," Environmental and Experimental Botany, vol. 84, pp. 44-51, 2012.

[68] D. Talukdar, "Arsenic-induced oxidative stress in the common bean legume, Phaseolus vulgaris L. seedlings and its amelioration by exogenous nitric oxide," Physiology and Molecular Biology of Plants, vol. 19, no. 1, pp. 69-79, 2013.

[69] D. Talukdar, "Studies on antioxidant enzymes in Canna indica plant under copper stress," Journal of Environmental Biology, vol. 34, no. 1, pp. 93-98, 2013.

[70] F. (Inci) Eyidoğan, H. A. Öktem, and M. Yücel, "Superoxide dismutase activity in salt stressed wheat seedlings," Acta Physiologiae Plantarum, vol. 25, no. 3, pp. 263-269, 2003.

[71] A. N. P. Hiner, J. N. Rodríguez-López, M. B. Arnao, E. L. Raven, F. García-Cánovas, and M. Acosta, "Kinetic study of the inactivation of ascorbate peroxidase by hydrogen peroxide," Biochemical Journal, vol. 348, pp. 321-328, 2000. 